Research Article

\title{
Dependence and Risk Spillover among Hedging Assets: Evidence from Bitcoin, Gold, and USD
}

\author{
Jiang Yu $\mathbb{D}^{1},{ }^{1}$ Yue Shang $\mathbb{D}^{2},{ }^{2}$ and Xiafei Li $\mathbb{D}^{1}$ \\ ${ }^{1}$ School of Economics and Management, Southwest Jiaotong University, Chengdu, China \\ ${ }^{2}$ School of Marxism, Yunnan University of Finance and Economics, Kunming, China \\ Correspondence should be addressed to Xiafei Li; 546602717@qq.com
}

Received 2 August 2021; Accepted 30 August 2021; Published 13 September 2021

Academic Editor: Dehua Shen

Copyright $(2021$ Jiang Yu et al. This is an open access article distributed under the Creative Commons Attribution License, which permits unrestricted use, distribution, and reproduction in any medium, provided the original work is properly cited.

Understanding the dependence and risk spillover among hedging assets is crucial for portfolio allocation and regulatory decision making. Using various copula and conditional Value-at-Risk ( $\mathrm{CoVaR})$ measures, this paper quantifies the dependence and risk spillover effects between three traditional and emerging hedging assets: Bitcoin, gold, and USD. Furthermore, we investigate these effects at various short- and long-term horizons using a variational model decomposition (VMD) method. The empirical results show that there is strong negative dependence between gold and USD, but Bitcoin and gold are weakly and positively connected. Secondly, risk spillovers exist only between Bitcoin and gold and between gold and USD. The risk spillover effect between Bitcoin and gold are not stable, that is, if Bitcoin or gold faces the downward or upward risk, both the downward and upward risk of another asset have the chance to increase. The negative risk spillover between gold and USD is stable, especially in long-term horizons. Finally, the risk spillover between Bitcoin and gold as well as between gold and USD are asymmetric at downward and upward market environment.

\section{Introduction}

In recent years, the global financial and energy markets have frequently experienced huge price volatility due to the increasing uncertainties in real economy and international geopolitical conflicts, etc. To deal with the increasing volatility/ risk in financial and energy markets, investors usually choose hedging assets like gold and US dollar (USD) to offset market risk and lock in profits [1-10]. Since Nakamoto [11] introduced the concept of Bitcoin, more and more investors have paid attentions to digital cryptocurrency, making digital cryptocurrency transactions play an increasingly prominent role in financial press and investment scene. Of all digital cryptocurrencies, Bitcoin typically has the largest trading volume. In December 2017, the Chicago Board Options Exchange (CBOE) and the Chicago Mercantile Exchange (CME) Group even launched the Bitcoin-based futures contracts. The financialization of Bitcoin and its characteristics of high returns and high volatility mean that any evidence of risk spillovers between Bitcoin and other financial assets would have major impact on risk management, investment portfolio management, and policy making [12-14]. Specially, Bitcoin shares some similarities with gold and USD. The Commodity Futures Trading Commission (CFTC) officially declared that though Bitcoin does not have legal tender status, it is a digital representation of value that can be used as a medium of exchange, a unit of account, and/or a store of value. Besides, several famous financial media like CNN and Bloomberg have labeled Bitcoin as the New Gold, and CFTC also declared virtual money a commodity like gold. These mean that if users of Bitcoin are rational, Bitcoin has some intrinsic value like gold. Besides, as a peer-to-peer electronic cash system, Bitcoin allow one party of transactions pays another directly online without going through a financial institution, thus having payment function and liquidity like USD. The research of Dyhrberg [15] has also proved that gold maximizes the attribute of value storage by sacrificing liquidity while USD maximizes liquidity by sacrificing storage value, but Bitcoin combines the characteristics of gold and USD and can be used for payments, portfolio management, and risk hedging like gold and USD. 
Other literature has also attempted to explore Bitcoin's ability to hedge market risks and found that it can be used for payment, portfolio management, and risk hedging [15-23]. However, some studies about the hedging capabilities of Bitcoin have found different results. For example, Baur et al. [13] found no significant relationship between Bitcoin and traditional asset classes by a regression analysis, suggesting that Bitcoin is more suitable for using as a speculative but not as a hedging asset. Klein et al. [19] also showed that Bitcoin is not the New Gold and has no hedging ability for stock market. This means that whether Bitcoin can replace the role of gold and USD as hedging assets in financial market remains controversial. So, it still makes sense to explore the linkage between Bitcoin and gold/USD.

As two commonly used hedging assets, the relationship between gold and USD has been widely explored [1, 5, 24-34]. These research studies demonstrate negative correlations between gold and USD by a variety of linear and nonlinear methods like VAR framework, ARDL model, spillover index, value-at-risk measures, copula functions, multivariate GARCH-class model, etc., suggesting that gold can be used as a hedge against a falling USD. The relationship between Bitcoin and gold as well as between Bitcoin and USD has also been explored in recent years [13, 19, 23, 35-41]. However, research studies on the relationship between Bitcoin and gold as well as between Bitcoin and USD yield some controversial results. For example, Baur et al. [13] found that Bitcoin return is uncorrelated to gold and USD returns by a linear regression analysis, whereas Bouri et al. [36] demonstrated that Bitcoin return correlated closely with gold and USD returns by a smooth transition VAR-GARCH-in-mean model. Besides, Bouri et al. [36] also showed that the sign of the spillovers between Bitcoin and gold/USD and the significance of the spillovers are different during bear and bull markets. However, Wang et al. [23] proved that there is no return spillover between Bitcoin and gold/currency, and volatility spillover exist only between Bitcoin and gold by a VAR-GARCH-BEKK model. Interesting, using different extensions to the NARDL model, Bouri et al. [37] found significant negative influence of gold and USD prices on Bitcoin price, whereas Jareño et al. [38] found significant positive connectedness between Bitcoin and gold. The findings of Bouri et al. [37] and Jareño et al. [38] both showed that the short-term and long-term influence of gold to Bitcoin is asymmetric. These two opposite results may due to the fact that the correlation between Bitcoin and gold/USD are dynamics, while these results are obtained in static models. The studies of Zwick and Syed [41] and Klein et al. [19] have illustrated this point. Zwick and Syed [41] showed that there is a structural break for the relationship between Bitcoin and gold prices. This structural break occurred on 5th October 2017. Gold negative correlated with Bitcoin before this time, whereas it correlated positively with Bitcoin after that. Klein et al. [19] obtained the dynamic correlation of Bitcoin and gold by a dynamic BEKK-GARCH model, observing that the correlation between Bitcoin and gold fluctuate around 0. Overall, the spillover between Bitcoin and gold/USD remains unclear, and exploring the complex relationship between them remains a key topic.
The research studies above suggest that the relationship between Bitcoin, gold, and USD may be dynamic and nonlinear. Besides, it may be asymmetry between bull and bear markets, and between short-term and long-term. This means that it would make sense to capture these characteristics simultaneously in a research process. For these considerations, we capture the nonlinear dependent structure between Bitcoin, gold, and USD by various static and dynamic bivariate copula functions and explore the risk spillover effect between them in upward and downward market environment by conditional value-at-risk (CoVaR) and deltaCoVaR ( $\triangle \mathrm{CoVaR})$ measurements described by Adrian and Brunnermeier [42]. Then, VMD technology is further utilized to explore the dependence structure and risk spillover effect in short-term and long-term horizons. TheCoVaR and $\triangle C o V a R$ measurements of Adrian and Brunnermeier [42] are widely used for quantifying the positive risk spillover effect from one financial market to another, that is, the possibility of market 1 facing the downward (upward) risk when a related market 2 facing a downward (upward) risk [43-49]. However, gold and USD are negatively correlated, and Klein et al. [19], Bouri et al. [37], and Zwick and Syed [41] also found that gold may be negatively correlated with Bitcoin. So, we extend the CoVaR measurements used in Ji et al. [50] and Ji et al. [51], further exploring the possibility of target market 1 facing the downward (upward) risk when the related market 2 facing an upward (downward) risk, i.e., negative risk spillover effect from market 2 to market 1 . As far as we know, only a few studies have explored the nonlinear interdependence and risk spillover effects between Bitcoin, gold, and USD by combining these approaches.

This paper contributes to the existing literature as we find some interesting results using the copula functions and the extended CoVaR measurements together with the VMD method. Our empirical results first find strong negative dependence between gold and USD, followed by the weak positive dependence between Bitcoin and gold but nearly no dependence between Bitcoin and USD. Besides, there is no risk spillover effect between Bitcoin and USD but unstable risk spillover effect between Bitcoin and gold. In other words, both the downward and the upward risk of Bitcoin (gold) have the chance to increase when gold (Bitcoin) facing the downward/upward risk. It confirms the view of Baur et al. [13] and Klein et al. [19] that Bitcoin may be more speculative and can hardly be used as an alternative currency and may have no stable hedging ability like gold, either. Moreover, there is stable negative risk spillover effect between gold and USD, especially in long-term horizons. Interestingly, in short-term horizons, when USD (gold) is facing the downward or upward risk, both the downward and upward risk of gold (USD) have the possibility to increase, indicting the stable hedging ability of gold in longterm horizons but unstable hedging power in short-term horizons. The risk spillover between gold and USD and from Bitcoin to gold is stronger in the upward market environment, while the risk spillover from gold to Bitcoin is stronger in the downward market environment. These empirical 
results have some important implications for investors and policy makers.

The rest of this paper is organized as follows: Section 2 describes the empirical methods utilized in this paper, Section 3 describes the data, Sections 4 and 5 discuss the empirical results, and Section 6 concludes the work.

\section{Methodology}

2.1. Model for Marginal Distribution. Before estimating the copula function, we employ the AR-GARCH-skew-t model to construct the marginal distribution of Bitcoin, gold, and USD index. In this model, the conditional mean is calculated by an $\mathrm{AR}(m)$ model:

$$
r_{t}=\phi_{0}+\sum_{i=1}^{m} \phi_{i} r_{t-i}+\varepsilon_{t}
$$

in which $\phi_{0}$ and $\phi_{i}$ are the parameters to be estimated, $m$ is the lag order of returns, and $\varepsilon_{t}=\sigma_{t} z_{t}, z_{t} \sim$ i.i.d. $D(0,1)$ is the error item. The conditional variance, $\sigma_{t}^{2}$, is given by a GARCH model:

$$
\sigma_{t}^{2}=\omega+\sum_{i=1}^{p} \alpha_{i} \varepsilon_{t-i}^{2}+\sum_{j=1}^{q} \beta_{j} \sigma_{t-j}^{2},
$$

where $\omega, \alpha_{i}, \beta_{j}$, and $\lambda_{i}$ are the parameters to be estimated and $\sum_{i}^{p} \alpha_{i}+\sum_{j}^{q} \beta_{j}$ should be smaller than $1, p$ and $q$ are the lag order of ARCH term and GARCH term, respectively. Brooks [52] proves that using a GARCH-class model with one lag order is sufficiently enough to describe the volatility clustering in asset returns. So, we set $m, p$, and $q$, to be one, constructing an AR (1)-GARCH $(1,1)$ model. To capture the fat tail and asymmetry distribution feature of Bitcoin, gold, and USD returns, we assume the i.i.d. random variable, $z_{t}$, follows the skewed- $t$ distribution [53]. The density of skew- $t$ distribution is given as follows:

$$
f\left(z_{t} ; v, \eta\right)= \begin{cases}b c\left(1+\frac{1}{v-2}\left(\frac{b z_{t}+a}{1-\eta}\right)^{2}\right)^{-((v+1) / 2)}, & z_{t}<-\frac{a}{b} \\ b c\left(1+\frac{1}{v-2}\left(\frac{b z_{t}+a}{1+\eta}\right)^{2}\right)^{-((v+1) / 2)}, & z_{t} \geq-\frac{a}{b}\end{cases}
$$

where $\quad a=4 \eta c(v-2)(v-1)^{-1}, \quad b^{2}=1+3 \eta-a^{2}, \quad$ and $c=\Gamma\left(2^{-1}(v+1)\right) / \sqrt{\pi(v-2)} ; v$ is the degree of freedom $(2<v \leq \infty)$; and $\eta$ is the asymmetric parameter $(-1<\eta<1)$. This skewed-t distribution will converge to a standard Gaussian distribution if $\eta=0$ and $v \longrightarrow \infty$ but will converge to the symmetric Student-t distribution if $\eta=0$ and $v$ is finite.

2.2. Copula Function. We explore the dependence structure between Bitcoin, gold, and USD using some bivariate copula functions. According to Sklar [54], a bivariate copula can couple two marginal distributions to represent a joint distribution function as

$$
F_{X Y}(x, y)=C\left(F_{X}(x), F_{Y}(y)\right),
$$

where $F_{X Y}(x, y)$ is the joint distribution function of two random variables $X$ and $Y ; F_{X}(x)$ and $F_{Y}(y)$ are the marginal distribution functions of $X$ and $Y$, respectively; and $C(u, v)$ for $u=F_{X}(x)$ and $v=F_{Y}(y)$ is uniquely determined on $\operatorname{Ran} F_{X} \times \operatorname{Ran} F_{Y}$ when margins are continuous.

Copula functions allow modeling for the dependence structures and marginal distributions, providing flexibility in characterizing dependence. Some copula functions can also capture the tail dependence, that is, the probability that two variables experience extreme upward or downward movement. The upper and lower tail dependence can be obtained by the following:

$$
\begin{aligned}
& \lambda_{U}=\lim _{u \longrightarrow 1} \operatorname{Pr}\left[X \geq F_{X}^{-1}(u) \mid Y \geq F_{Y}^{-1}(u)\right]=\lim _{u \longrightarrow 1} \frac{1-2 u+C(u, u)}{1-u}, \\
& \lambda_{L}=\lim _{u \longrightarrow 0} \operatorname{Pr}\left[X \leq F_{X}^{-1}(u) \mid Y \leq F_{Y}^{-1}(u)\right]=\lim _{u \longrightarrow 0} \frac{C(u, u)}{u},
\end{aligned}
$$

where $\lambda_{U}, \lambda_{L} \in[0,1]$. If $\lambda_{L}>0\left(\lambda_{U}>0\right)$, there is a lower (upper) tail dependence.

To obtain more accurate dependence characteristics, seven copula functions with different tail dependence characteristics are considered in this study. These copula functions are specified as follows:

(1) Gaussian Copula. Gaussian copula function is given by

$$
C_{N}(u, v ; \rho)=\Phi\left(\Phi^{-1}(u), \Phi^{-1}(v)\right)
$$

where $\rho \in[-1,1]$ is the correlation parameter; $\Phi$ is the standard Gaussian cumulative distribution function; $\Phi^{-1}(u)$ and $\Phi^{-1}(v)$ are standard Gaussian quantile functions. The tail dependence of this copula function is zero, i.e., $\lambda_{U}=\lambda_{L}=0$.

(2) Student-t Copula. Student-t copula function is defined as

$$
C_{\mathrm{ST}}(u, v ; \rho, v)=T\left(t_{v}^{-1}(u), t_{v}^{-1}(v)\right),
$$

in which $v$ is the parameter of degree-of-freedom, $t_{v}^{-1}(u)$ and $t_{v}^{-1}(v)$ are the quantile functions of Student- $t, T$ is the bivariate Student- $t$ cumulative distribution function. This copula function has symmetric nonzero tail dependence, and the tail dependence can be obtained by

$$
\lambda_{U}=\lambda_{L}=2 t_{v+1}\left(\frac{-\sqrt{v+1} \sqrt{1-\rho}}{\sqrt{1+\rho}}\right) .
$$

(3) Clayton Copula. Clayton copula function is defined as

$$
C_{\mathrm{CL}}(u, v ; \delta)=\max \left\{\left(u^{-\delta}+v^{-\delta}-1\right)^{-1 / \delta}, 0\right\} .
$$

It allows for lower tail dependence and upper tail independence, i.e., $\lambda_{L}=2^{-1 / \delta}(\delta \geq-1)$ and $\lambda_{U}=0$. 
(4) Rotated Clayton Copula. Rotated Clayton copula is defined as

$C_{\mathrm{RCL}}(u, v ; \delta)=u+v-1+C_{\mathrm{CL}}(1-u, 1-v ; \delta)$,

and it is a copula function with lower tail independence and upper tail dependence, that is $\lambda_{L}=0$, $\lambda_{U}=2^{-1 / \delta}(\delta \geq-1)$.

(5) Gumbel Copula. Gumbel copula is defined as

$$
C_{G}(u, v ; \delta)=\exp \left(-\left((-\log u)^{\delta}+(-\log v)^{\delta}\right)^{1 / \delta}\right) .
$$

The tail dependence of this copula function is asymmetric with lower tail independence and upper tail dependence, thus, $\lambda_{L}=0, \lambda_{U}=2-2^{1 / \delta}(\delta \geq 1)$.

(6) Rotated Gumbel Copula. Rotated Gumbel copula is defined as

$C_{\mathrm{RG}}(u, v ; \delta)=u+v-1+C_{G}(1-u, 1-v ; \delta)$.

In contrast to the Gumbel copula, this copula function has lower tail dependence but no upper tail dependence, i.e., $\lambda_{L}=2-2^{1 / \delta}(\delta \geq 1), \lambda_{U}=0$.

(7) SJC (symmetrized Joe-Clayton) Copula. SJC copula is given by

$$
C_{\mathrm{SJC}}\left(u, v ; \lambda_{U}, \lambda_{L}\right)=0.5\left(C_{\mathrm{JC}}\left(u, v ; \lambda_{U}, \lambda_{L}\right)+C_{\mathrm{JC}}\left(1-u, 1-v ; \lambda_{U}, \lambda_{L}\right)+u+v-1\right)
$$

where $C_{\mathrm{JC}}\left(u, v ; \lambda_{U}, \lambda_{L}\right)$ is the Joe-Clayton,

$$
C_{\mathrm{JC}}\left(u, v ; \lambda_{U}, \lambda_{L}\right)=1-\left(1-\left\{\left[1-(1-u)^{\kappa}\right]^{-\gamma}+\left[1-(1-v)^{\kappa}\right]^{-\gamma}-1\right\}^{-1 / \gamma}\right)^{1 / \kappa},
$$

in which $\lambda_{L} \in(0,1), \lambda_{U} \in(0,1), \quad \kappa=1 / \log _{2}\left(2-\lambda_{U}\right)$ and $\gamma=-1 / \log _{2}\left(\lambda_{L}\right)$. The SJC copula has the special symmetric tail dependence, that is, $\lambda_{L}=\lambda_{U}$.

Considering the possible time-varying dependence between two variables, we further construct the time-varying copulas by allowing the dependence parameters of the seven copula functions to be dynamic. For the Gaussian copula function with time-varying parameters (TVP Gaussian), the dynamic of dependence parameter, $\rho_{t}$, follow an ARMA (1, q) process [55]:

$$
\rho_{t}=\Lambda\left(\psi_{0}+\psi_{1} \rho_{t-1}+\psi_{2} \frac{1}{q} \sum_{j=1}^{q} \Phi^{-1}\left(u_{t-j}\right) \cdot \Phi^{-1}\left(v_{t-j}\right)\right),
$$

where $\Lambda(x)=\left(1-e^{-x}\right)\left(1+e^{-x}\right)^{-1}$ is the modified logistic transformation, which can keep $\rho_{t}$ in $(-1,1)$ and $\psi_{0}, \psi_{1}$, and $\psi_{2}$ are the parameters to be estimated.

For the Student- $t$ copula, two dynamic forms of dependency parameter are considered. One is to make the correlation parameter $\rho$ to change over time, but the degree of freedom $v$ remain constant. In this time-varying Student- $t$ copula, the dynamic of $\rho$ is given in equation (15) by substituting $\Phi^{-1}(x)$ with $t_{v}^{-1}(x)$. However, research have shown that the degree of freedom parameter is unlikely to remain constant over time [56-59]. Because both $\rho$ and $v$ are important parameters for measuring the copula cumulative distribution function and the tail dependence, we further consider another time-varying form for Student- $t$ copula function. This copula function allows both $\rho$ and $v$ to be time varying, and $v$ is evolved in [60]:

$$
v_{t}=\Psi\left(\theta_{0}+\theta_{1} v_{t-1}+\theta_{2} \frac{1}{q} \sum_{j=1}^{q} t_{t-j}^{-1}\left(u_{t-j}\right) \cdot t_{t-j}^{-1}\left(v_{t-j}\right)\right),
$$

where $\Psi(x)=2\left(1+50 e^{x}\right)\left(1+e^{x}\right)^{-1}$ is the logistic transformation for keeping $v_{t}$ in $(0,100)$.

For the SJC copula, the evolutions of the tail dependence parameters follow

$$
\begin{aligned}
& \lambda_{t}^{U}=\Delta\left(\omega_{U}+\beta_{U} \rho_{t-1}+\alpha_{U} \frac{1}{q} \sum_{i=1}^{q}\left|u_{t-i}-v_{t-i}\right|\right), \\
& \lambda_{t}^{L}=\Delta\left(\omega_{L}+\beta_{L} \rho_{t-1}+\alpha_{L} \frac{1}{q} \sum_{i=1}^{q}\left|u_{t-i}-v_{t-i}\right|\right),
\end{aligned}
$$

where $\Delta(x)$ denotes the logistic transformation, $\Delta(x)=\left(1+e^{-x}\right)^{-1}$ that keeps the parameters of the timevarying SJC copula in $(0,1)$.

For other four copula functions, the parameters evolve as

$$
\delta_{t}=\omega+\beta \delta_{t-1}+\alpha \frac{1}{q} \sum_{i=1}^{q}\left|u_{t-i}-v_{t-i}\right| .
$$

2.3. Measurements for $V a R$ and CoVaR. In this study, we quantify the downside and upside risk of Bitcoin, gold and USD by the downside and upside Value-at-Risk (VaR). The downside risk, $\operatorname{VaR}_{t}^{D, \alpha}$, for a confidence level $1-\alpha$ at time $t$ is given by $\operatorname{Pr}\left(r_{t} \leq \mathrm{VaR}_{t}^{D, \alpha}\right)=\alpha$, which is the $\alpha$ quantile of the distribution of return series. Similarly, the upside risk, $\mathrm{VaR}_{t}^{U, \alpha}$, is the $(1-\alpha)$ quantile of the distribution of return series, that is $\operatorname{Pr}\left(r_{t} \geq \mathrm{VaR}_{t}^{U, \alpha}\right)=\alpha$. These two risks can be measured from marginal distribution models as $\mathrm{VaR}_{t}^{D, \alpha}=$ $\mu_{t}+\sigma_{t} t_{v, \eta}^{-1}(\alpha)$ and $\mathrm{VaR}_{t}^{U, \alpha}=\mu_{t}+\sigma_{t} t_{v, \eta}^{-1}(1-\alpha)$, respectively, where, $\mu_{t}$ is the conditional mean from equation (1) $\sigma_{t}$ is the 
conditional standard deviation from equation $(2), t_{v, \eta}^{-1}(\alpha)$ is the $\alpha$ quantile of the skewed Student $t$ distribution.

To quantify the risk spillover effects between Bitcoin, gold, and USD, the conditional value-at-risk (CoVaR) proposed by Adrian and Brunnermeier [42] is utilized. CoVaR considers the correlation between two assets and quantifies the risk of asset 1 when a correlated asset 2 suffers extreme risks. Given two potentially correlated asset return series, $r_{1, t}$ and $r_{2, t}$, the downside and upside CoVaR of asset 1 are generally expressed as

$$
\begin{gathered}
\operatorname{Pr}\left(r_{1, t} \leq \operatorname{CoVaR}_{1 \mid 2 D, t}^{D, \alpha} \mid r_{2, t} \leq \operatorname{VaR}_{2, t}^{D, \beta}\right)=\alpha, \\
\operatorname{Pr}\left(r_{1, t} \geq \operatorname{CoVaR}_{1 \mid 2 U, t}^{U, \alpha} \mid r_{2, t} \geq \operatorname{VaR}_{2, t}^{U, \beta}\right)=\alpha,
\end{gathered}
$$

respectively, where $\alpha$ and $\beta$ are the significant level of asset 1 and asset 2 , respectively, and $\mathrm{CoVaR}_{1 \mid 2 D, t}^{D, \alpha}\left(\mathrm{CoVaR}_{1 \mid 2 U, t}^{U, \alpha}\right)$ is the downward (upward) risk of asset 1 when the correlated asset 2 is extreme downward (upward) movement. In combination with the copula function, equations (19) and (20) can be rewritten as

$$
\begin{array}{r}
C\left(F_{1, t}\left(\operatorname{CoVaR}_{1 \mid 2 D, t}^{D, \alpha}\right), F_{2, t}\left(\operatorname{VaR}_{2, t}^{D, \beta}\right)\right)-\alpha \beta=0, \\
F_{1, t}\left(\operatorname{CoVaR}_{1 \mid 2 U, t}^{U, \alpha}\right)-C\left(F_{1, t}\left(\operatorname{CoVaR}_{1 \mid 2 U, t}^{U, \alpha}\right), F_{2, t}\left(\operatorname{VaR}_{2, t}^{U, \beta}\right)\right)-\beta+\alpha \beta=0,
\end{array}
$$

respectively, where $F_{1, t}$ and $F_{2, t}$ are the marginal distribution of asset 1 and asset 2 , respectively, $C\left(F_{1, t}, F_{2, t}\right)$ is the joint distribution function of the best-fitted copula function. (We measure the CoVaR based on the best-fitted copula function mainly because that the more accurate copula cumulative distribution is helpful for obtaining the more accurate risk spillover characteristics.)

Equations (19)-(22) are useful for capturing the positive risk spillovers between two markets. However, because gold and USD are negatively correlated, the CoVaR measurements above may no longer applicable. In order to capture the possible negative risk spillovers between two markets, we refer to Ji et al. [50] and Ji et al. [51] and consider another two kinds of CoVaRs, $\mathrm{CoVaR}_{1 \mid 2 U, t}^{D, \alpha}$ and $\mathrm{CoVaR}_{1 \mid 2 D, t}^{U, \alpha}$. $\mathrm{CoVaR}_{1 \mid 2 U, t}^{D, \alpha}$ is the downside risk of asset 1 conditional on the fact that the correlated asset 2 exhibits the extreme upward movement, and $\mathrm{CoVaR}_{1 \mid 2 D, t}^{U, \alpha}$ is the upside risk of asset 1 conditional on the extreme downward movement of asset 2 . These two CoVaRs can be expressed as

$$
\begin{aligned}
& \operatorname{Pr}\left(r_{1, t} \leq \mathrm{CoVaR}_{1 \mid 2 U, t}^{D, \alpha} \mid r_{2, t} \geq \operatorname{VaR}_{2, t}^{U, \beta}\right)=\alpha, \\
& \operatorname{Pr}\left(r_{1, t} \geq \mathrm{CoVaR}_{1 \mid 2 D, t}^{U, \alpha} \mid r_{2, t} \leq \operatorname{VaR}_{2, t}^{D, \beta}\right)=\alpha,
\end{aligned}
$$

respectively. Similarity, $\mathrm{CoVaR}_{1 \mid 2 U, t}^{D, \alpha}$ and $\mathrm{CoVaR}_{1 \mid 2 D, t}^{U, \alpha}$ can be rewritten as the following equations:

$$
\begin{aligned}
& F_{1, t}\left(\mathrm{CoVaR}_{1 \mid 2 U, t}^{D, \alpha}\right)-C\left(F_{1, t}\left(\operatorname{CoVaR}_{1 \mid 2 U, t}^{D, \alpha}\right), F_{2, t}\left(\operatorname{VaR}_{2, t}^{U, \beta}\right)\right)-\alpha \beta=0, \\
& C\left(F_{1, t}\left(\operatorname{CoVaR}_{1 \mid 2 D, t}^{U, \alpha}\right), F_{2, t}\left(\operatorname{VaR}_{2, t}^{D, \beta}\right)\right)-\beta+\alpha \beta=0,
\end{aligned}
$$

Following the two-step procedure of Reboredo and Ugolini [48], we can obtain the CoVaRs by measuring equations (21) and (22) and (24) and (25). If CoVaRs stronger than corresponding $V a R s$, the risk spillover exists. The significance of risk spillover can then be test by comparing the difference between the CoVaRs and $\mathrm{VaR}$ of asset 1, employing theeeee Kolmogorov-Smirnov (KS) bootstrapping test of Abadie [61].
Finally, to quantify the systemic risk contribution (risk spillover) of asset 2 to asset 1 , four delta CoVaRs ( $\triangle \mathrm{CoVaR}$ ) are employed. $\triangle \mathrm{CoVaRs}$ can describe the difference between the risk of asset 1 conditional on the extreme movement of the correlated asset 2 and the risk of asset 1 conditional on the normal state of asset 2. Let $\Delta \mathrm{CoVaR}_{1 \mid 2}^{D, \alpha}$ t $\left(\Delta \mathrm{CoVaR}_{1 \mid 2 U, t}^{U, \alpha}\right)$ represents the growth rate of the downside (upside) risk of asset 1 when asset 2 is from normal state to extreme downward (upward) movement. Similarly, let $\Delta \mathrm{CoVaR}_{1 \mid 2 U, t}^{D, \alpha}\left(\Delta \mathrm{CoVaR}_{1 \mid 2 D, t}^{U, \alpha}\right)$ be the growth rate of the downside (upside) risk of asset 1 when asset 2 is from normal state to extreme upward (downward) movement. Positive $\triangle \mathrm{CoVaR}$ indicates that there may be positive or negative risk spillover from asset 2 to asset 1 . These four $\Delta C o V a R s$ can be defined as the following four equations:

$$
\begin{gathered}
\Delta \operatorname{CoVaR}_{1 \mid 2 D, t}^{D, \alpha}=\frac{\left(\operatorname{CoVaR}_{1 \mid 2 D, t}^{D, \alpha}-\operatorname{CoVaR}_{1 \mid 2 M, t}^{D, \alpha}\right)}{\operatorname{CoVaR}_{1 \mid 2 M, t}^{D, \alpha}}, \\
\Delta \operatorname{CoVaR}_{1 \mid 2 U, t}^{U, \alpha}=\frac{\left(\operatorname{CoVaR}_{1 \mid 2 U, t}^{U, \alpha}-\operatorname{CoVaR}_{1 \mid 2 M, t}^{U, \alpha}\right)}{\operatorname{CoVaR}_{1 \mid 2 M, t}^{U, \alpha}}, \\
\Delta \operatorname{CoVaR}_{1 \mid 2 U, t}^{D, \alpha}=\frac{\left(\operatorname{CoVaR}_{1 \mid 2 U, t}^{D, \alpha}-\operatorname{CoVaR}_{1 \mid 2 M, t}^{D, \alpha}\right)}{\operatorname{CoVaR}_{1 \mid 2 M, t}^{D, \alpha}}, \\
\Delta \operatorname{CoVaR}_{1 \mid 2 D, t}^{U, \alpha}=\frac{\left(\operatorname{CoVaR}_{1 \mid 2 D, t}^{U, \alpha}-\operatorname{CoVaR}_{1 \mid 2 M, t}^{U, \alpha}\right)}{\operatorname{CoVaR}_{1 \mid 2 M, t}^{U, \alpha}},
\end{gathered}
$$

where $\operatorname{CoVaR}_{1 \mid 2 M}^{D, \alpha}$ and $\operatorname{CoVaR}_{1 \mid 2 M}^{U, \alpha}$ satisfies $\operatorname{Pr}\left(r_{1, t} \leq\right.$ $\left.\mathrm{CoVaR}_{1 \mid 2 M, t}^{D, \alpha} \mid F_{2, t}\left(r_{2, t}\right)=0.5\right)=\alpha$ and $\operatorname{Pr}\left(r_{1, t} \geq \mathrm{CoVaR}_{1 \mid 2 M, t}^{U, \alpha}\right.$ $\left.\mid F_{2, t}\left(r_{2, t}\right)=0.5\right)=\alpha$, respectively.

\section{Data and Summary Statistics}

The data we utilized in this article include the daily prices for Bitcoin, gold, and USD index from 1 May, 2013 to 31 July, 2019. Bitcoin price is downloaded from https:// coinmarketcap.com/. The gold prices and USD index are 
collected from Federal Reserve Bank of St. Louis (https:// fred.stlouisfed.org/). The price and return dynamics of daily Bitcoin, gold and USD indices are drawn in Figures 1 and 2, respectively.

Table 1 presents the summary statistics of Bitcoin, gold, and USD returns. We find in Table 1 that the mean and median of gold return series are negative, whereas the mean and median of the return of other two assets are positive, and Bitcoin returns have the largest mean and median. Besides, the standard deviation of Bitcoin return is also bigger than other two series. Positive skewness statistics indicate that the distribution of our three asset return series is right skewed. The kurtosis statistics for all series are greater than 3, indicating that their distribution has the characteristic of peak. We can also find that all the return series are not normally distributed because their Jarque-Bera statistics are significant at $1 \%$ levels. ADF statistics proved the stationarity of all series. The statistics of Ljung-Box test for returns and squared returns indicate the presence of autocorrelation in gold and Bitcoin returns. Specially, although the squared return of USD is autocorrelative, the return of it is weak autocorrelative. The LM tests for ARCH effect indicate the significant conditional heteroscedasticity effect for all return series.

\section{Tests for Risk Spillover Effect}

4.1. Estimation Results for Marginal Models. The estimation results for the parameters of three marginal models (AR (1)GARCH $(1,1)$-skew- $t$ ) are presented in Table 2. Table 2 shows firstly that the $\operatorname{AR}$ coefficient $\left(\phi_{1}\right)$ of our marginal distribution models are not significant for three asset return series. Besides, $\alpha_{1}$ and $\beta_{1}$ are significant for all marginal distribution models, implying obvious ARCH effect and volatility clustering in three return series. Furthermore, the tail parameters of three models are significantly positive, meaning that the residual series of these models are fat tailed. The asymmetry parameter for USD model is significantly positive, indicating that the standardized residual of this model is right skewed. However, the asymmetry parameters for gold and Bitcoin returns are not significant. The $p$ values of the KS test are larger than 0.1 , indicating that the skew- $t$ distribution is a good description for three marginal distributions, and then, the dependence structure between Bitcoin, gold, and USD can be measured by the copula functions in the next step.

4.2. Estimation Results for Copula Functions. In this subsection, we estimate the dependence structure of each assets pair using various static and time-varying copula functions. The best-fitted copula function is selected by the AIC criterion, and the AIC for each copula function is presented in Table 3 . Table 3 shows that time-varying copula functions fit better than static ones. The dependence structure between Bitcoin and gold and between gold and USD can be better described by the Student- $t$ copula function with two dynamic parameters, $\rho_{t}$ and $v_{t}$ (i.e., "TVP-Student 2 " in Table 3 ), indicating the symmetric tail dependence of gold and other two assets. However, TVP-Gaussian copula function is the best-fitted one for describing the dependence structure between Bitcoin and USD, indicating an average dependence of these two assets.

Figure 3 shows the evolutions of the dependence of three asset pairs and presents the mean of each dynamic dependence parameter. The dependence structures draw in Figure 3 comes from the best-fitted copula functions. The dynamic dependence parameter between Bitcoin and gold drawn in the top panel of Figure 3 shows that the dependence between these two assets fluctuates around a small positive mean at 0.032 . The middle panel of Figure 3 shows that the dependence between Bitcoin and USD has a mean that is very close to 0 . The dependence between gold and USD, however, fluctuates around a strong negative mean, at -0.295 , as shown in the bottom panel of Figure 3. In summary, gold and USD show the strongest dependency, followed by gold and Bitcoin, whereas there is weakest dependency between Bitcoin and USD.

4.3. Tests for Risk Spillover Effect. To explore the risk spillover effect between gold, Bitcoin, and USD, we measure the VaRs and CoVaRs for each asset. The evolution of $V a R s$ and CoVaRs are drawn in Figure 4. Panel A of Figure 4 show the VaRs and CoVaRs of Bitcoin-gold pair, and the left one draws the CoVaRs of Bitcoin conditional on gold, the right one shows the CoVaRs of gold conditional on Bitcoin. Panel B draws the VaRs and CoVaRs of Bitcoin-USD pair, and the left one and the right one shows the CoVaRs of Bitcoin conditional on USD and USD conditional on Bitcoin, respectively. Panel C presents the VaRs and CoVaRs of gold-USD pair, and the right one draws the CoVaRs of gold conditional on USD, the left draws the CoVaRs of USD conditional on gold. We can find in Figure 4 that the risk spillover between Gold and USD are more pronounced; however, the negative risk spillovers between other asset pairs are still need to be verified mathematically.

Columns 2-4 and columns 7-9 of Table 4 list the mean and standard deviations of VaRs and CoVaRs of each asset pairs. We can find in Table 4 that both the mean of $\mathrm{CoVaR}_{1 \mid 2 D}^{D, \alpha}$ and $\mathrm{CoVaR}_{1 \mid 2 U}^{D, \alpha}$ of Bitcoin conditional on gold are stronger than the downside $V a R$ of Bitcoin, and the mean of $\mathrm{CoVaR}_{1 \mid 2 U}^{U, \alpha}$ and $\mathrm{CoVaR}_{1 \mid 2}^{U, \alpha}$ are also stronger than the upside $V a R$. Similarly, $\operatorname{CoVaR}_{1 \mid 2 D}^{D, \alpha}$ and $\operatorname{CoVaR}_{1 \mid 2 U}^{D, \alpha}$ of gold conditional on Bitcoin are stronger than the downside $V a R$ of gold, and the $\operatorname{CoVaR}_{1 \mid 2 U}^{U, \alpha}$ and $\operatorname{CoVaR}_{1 \mid 2 D}^{U, \alpha}$ are also stronger than the upside $V a R$. These suggest that there may be unstable risk spillovers between Bitcoin and gold. As for the Bitcoin-USD pairs, we can only find a weak increase of $\mathrm{CoVaR}_{1 \mid 2 D}^{D, \alpha}$ and $\mathrm{CoVaR}_{1 \mid 2 U}^{U, \alpha}$ of Bitcoin with respect to VaRs of Bitcoin, meaning a weak positive risk spillover effect between Bitcoin and USD. For the gold-USD pairs, we found that $\mathrm{CoVaR}_{1 \mid 2 D}^{D, \alpha}$ and $\mathrm{CoVaR}_{1 \mid 2 U}^{U, \alpha}$ for each of these two asset are lower than the corresponding VaRs, while $\operatorname{CoVaR}_{1 \mid 2 U}^{D, \alpha}$ and $\mathrm{CoVaR}_{1 \mid 2 D}^{U, \alpha}$ of them are stronger than the corresponding $\mathrm{VaRs}$, indicating a negative risk spillover effect between gold and USD. 

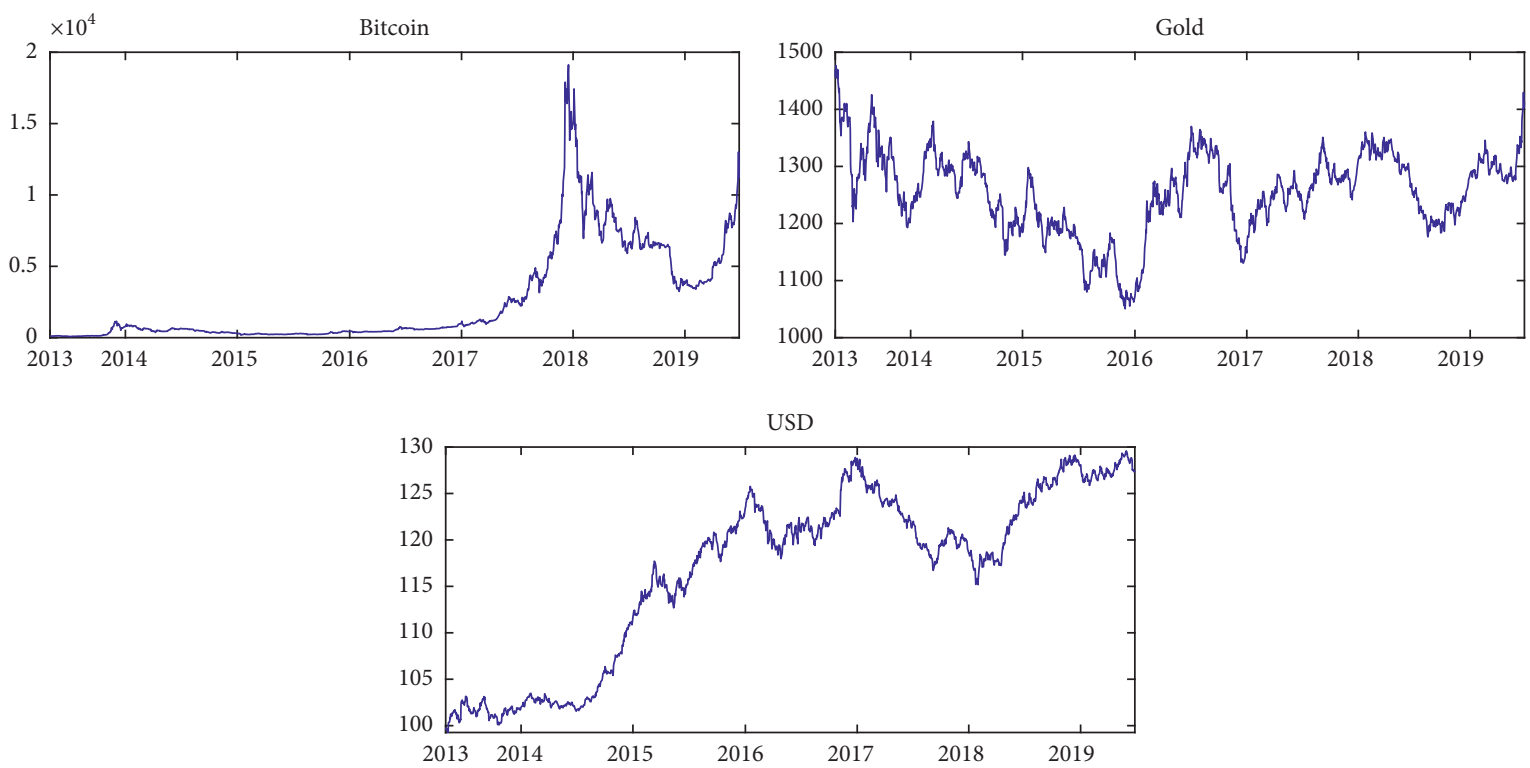

FIgURE 1: Time variations of daily prices of (a) Bitcoin, (b) gold, and (c) USD indices.
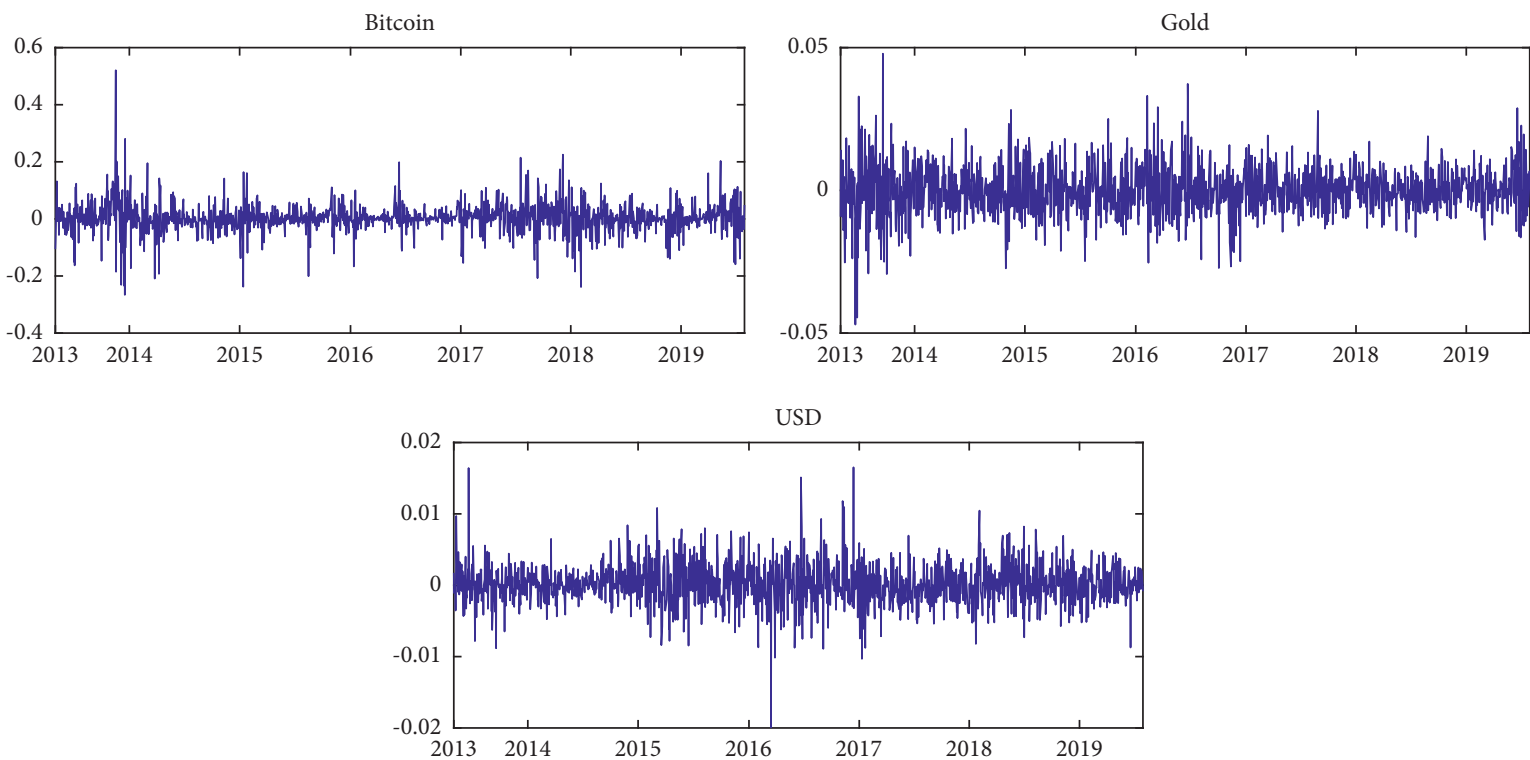

FIgURE 2: Daily returns of (a) Bitcoin, (b) gold, and (c) USD.

To further confirm the existence of risk spillover effect between gold, Bitcoin, and USD, Kolmogorov-Smirnov (KS) test of Abadie [61] is utilized. The KS statistic can be defined as

$$
\mathrm{KS}_{m n}=\left(\frac{m n}{m+n}\right)^{1 / 2} \sup _{x}\left|F_{m}(x)-F_{n}(x)\right|,
$$

where $m$ and $n$ are the size of two samples, respectively. $F_{m}$ $(x)$ and $F_{n}(x)$ are the corresponding cumulative distribution functions of these two samples. The KS test in this subsection test the null hypothesis that the CoVaR of asset 1 conditional on asset 2 is no stronger than the $V a R s$ of asset 1 . If the null hypothesis is rejected, the risk spillover from asset 2 to asset 1 is significantly exist. The results of KS test are listed in Table 5. The $p$ values that are lower than 0.1 are marked with bold. As shown in Table 5, the null hypothesis of no positive and negative system risk spillover between Bitcoin and gold market are rejected at $10 \%$ significant level, indicating the unstable risk spillover effect between Bitcoin and gold market. Then, the hypothesis of no positive and negative risk spillover between Bitcoin and USD cannot be rejected, suggesting that there are no significant risk spillover effects between these two assets. Finally, the results of KS test cannot reject the null hypothesis of no positive system risk spillover between gold and USD market, whereas the null hypothesis of no negative system risk spillover between these two assets are 
TABLE 1: Summary statistics and unconditional correlations.

\begin{tabular}{lccc}
\hline & Bitcoin & Gold & USD \\
\hline Obs & 1579 & 1579 & 1579 \\
Mean (\%) & 0.282 & -0.002 & 0.016 \\
Max & 0.521 & 0.048 & 0.017 \\
Min & -0.266 & -0.047 & -0.020 \\
Median (\%) & 0.212 & -0.013 & 0.000 \\
Std. dev & 0.051 & 0.008 & 0.003 \\
Skewness & 0.408 & 5.453 & 0.159 \\
Kurtosis & 13.7053 & $396.093^{* * *}$ & 6.717 \\
J-B & $7583.263^{* * *}$ & $-38.952^{* * *}$ & $915.751^{* * *}$ \\
ADF & $-41.240^{* * *}$ & 8.342 & $-39.084^{* * *}$ \\
Q (5) & $18.502^{* * *}$ & $26.263^{* * *}$ & 2.801 \\
Q (10) & $24.306^{* * *}$ & $92.277^{* * *}$ & 9.752 \\
$Q^{2}(5)$ & $103.103^{* * *}$ & $76.376^{* * *}$ & $15.979^{* * *}$ \\
ARCH (5) & $87.66^{* * *}$ & $13.650^{* * *}$ \\
\hline
\end{tabular}

Note: this table presents the summary statistics of gold, Bitcoin and USD returns and lists the unconditional correlations between gold and Bitcoin and USD returns. Obs., Mean, Max., Min, Median, and Std. dev. describe the observations, mean value, maximum, minimum, median, and standard deviation of each return series, respectively. J-B is the Jarque-Bera statistics [62] for normality test. ADF summarizes the statistic of Augmented Dickey-Fuller [63] unit root test. Q (5) and Q (10) denote the Ljung-Box statistics [64] for autocorrelation test of the return series for up to $5^{\text {th }}$ and $10^{\text {th }}$ lags, respectively. $Q^{2}(5)$ is the Ljung-Box statistics for autocorrelation test of the squared return series. ARCH (5) refers to the statistics of Engle's [65] LM test for autoregressive conditional heteroscedasticity $(\mathrm{ARCH})$ effect. The symbols ${ }^{* * *},{ }^{* *}$, and ${ }^{*}$ denote significance at the $1 \%, 5 \%$, and $10 \%$ levels, respectively.

TABle 2: Parameters estimates of marginal models.

\begin{tabular}{|c|c|c|c|}
\hline & Bitcoin & Gold & USD \\
\hline$\phi_{0}$ & $\begin{array}{c}0.002 \\
(9.029 e-04) \\
\end{array}$ & $\begin{array}{l}-1.933 e-05 \\
(1.929 e-04) \\
\end{array}$ & $\begin{array}{c}1.540 e-04 \\
(6.504 e-05) \\
\end{array}$ \\
\hline$\phi_{1}$ & $\begin{array}{l}-0.022 \\
(0.040) \\
\end{array}$ & $\begin{array}{c}0.036 \\
(0.025) \\
\end{array}$ & $\begin{array}{c}0.003 \\
(0.024) \\
\end{array}$ \\
\hline$\omega$ & $\begin{array}{c}3.124 e-05 \\
(1.950 e-05)\end{array}$ & $\begin{array}{c}6.013 e-07 \\
(3.148 e-07)\end{array}$ & $\begin{array}{c}3.049 e-08 \\
(2.173 e-08)\end{array}$ \\
\hline$\alpha_{1}$ & $\begin{array}{c}0.144^{* * *} \\
(0.020)\end{array}$ & $\begin{array}{c}0.036^{* * * *} \\
(0.011) \\
\end{array}$ & $\begin{array}{c}0.031^{* * *} \\
(0.007) \\
\end{array}$ \\
\hline$\beta_{1}$ & $\begin{array}{c}0.856^{* * *} \\
(0.029) \\
\end{array}$ & $\begin{array}{c}0.955^{* * *} \\
(0.013)\end{array}$ & $\begin{array}{c}0.966^{* * *} \\
(0.007)\end{array}$ \\
\hline Asymmetry & $\begin{array}{l}-0.027 \\
(0.040)\end{array}$ & $\begin{array}{c}0.042 \\
(0.057)\end{array}$ & $\begin{array}{l}0.064^{*} \\
(0.032)\end{array}$ \\
\hline Tail & $\begin{array}{c}3.054^{* * *} \\
(0.134)\end{array}$ & $\begin{array}{c}9.349^{* * *} \\
(2.026)\end{array}$ & $\begin{array}{c}5.794^{* * *} \\
(0.855)\end{array}$ \\
\hline KS test & {$[0.107]$} & {$[0.955]$} & [0.333] \\
\hline
\end{tabular}

Note: this table shows the parameters estimates and standard errors (in parentheses) for the marginal models with skewed-t distribution. KS test reports the $p$ value (in square brackets) of the Kolmogorov-Smirnov test, representing the adequacy of the skewed-t distribution. The null hypothesis of the Kolmogorov-Smirnov test cannot be rejected when $p$ values is greater than 0.1 . The symbols ${ }^{* * *},{ }^{* *}$, and ${ }^{*}$ denote significance at the $1 \%, 5 \%$, and $10 \%$ levels, respectively.

rejected at $10 \%$ significant level, confirming the stable negative risk spillover between USD and gold market.

Then, we calculate the $\Delta C o V a R s$ for each asset pairs to quantify the risk contribution (risk spillover) of each asset to another. The dynamics of $\Delta C o V a R s$ are drawn in Figure 5, and the mean and standard deviation of $\triangle C o V a R s$ are shown in column 5-6 and column 10-11 of Table 4. Figure 5 and Table 4 show that $\Delta \operatorname{CoVaR}_{1 \mid 2 D}^{D, \alpha}, \Delta \operatorname{CoVaR}_{1 \mid 2 U}^{U, \alpha}, \Delta \operatorname{CoVaR}_{1 \mid 2 U}^{D, \alpha}$, and $\Delta \mathrm{CoVaR}_{1 \mid 2 D}^{U, \alpha}$ from gold to Bitcoin and from Bitcoin to gold fluctuate around positive means, indicating the possible unstable risk spillover between Bitcoin and gold. $\triangle \operatorname{CoVaR}_{1 \mid 2 D}^{D, \alpha}$ and $\Delta \mathrm{CoVaR}_{1 \mid 2 U}^{U, \alpha}$ from gold to Bitcoin as well as from Bitcoin to gold have stronger mean than $\Delta \operatorname{CoVaR}_{1 \mid 2 U}^{D, \alpha}$ and
$\Delta \mathrm{CoVaR}_{1 \mid 2 D}^{U, \alpha}$, meaning the dominant of positive risk spillover effect. The $\triangle C o V a R s$ of Bitcoin-USD pair, however, fluctuates around the values, which are very close to zero. For the goldUSD pairs, $\Delta \mathrm{CoVaR}_{1 \mid 2 U}^{D, \alpha}$ and $\Delta \mathrm{CoVaR}_{1 \mid 2 D}^{U, \alpha}$ from USD to gold as well as from gold to USD fluctuate around the higher positive means, whereas $\Delta \operatorname{CoVaR}_{1 \mid 2 D}^{D, \alpha}$ and $\Delta \operatorname{CoVaR}_{1 \mid 2 U}^{U, \alpha}$ fluctuate around smaller negative means, indicating a major negative risk spillover between gold and USD. These findings further confirm the results of KS test.

4.4. Tests for Asymmetric Downside and Upside Risk Spillover Effect. Table 4 also shows that downside $\triangle C o V a R s$ from gold to Bitcoin are larger than upside $\Delta C o V a R s$, whereas 
TABLE 3: Results of copula function.

\begin{tabular}{lccc}
\hline & Bitcoin and gold & Bitcoin and USD & Gold and USD \\
\hline Gaussian & -1.627 & 0.001 & -138.552 \\
Clayton & -0.536 & 0.003 & 0.068 \\
Rotated Clayton & -4.044 & -0.010 & 0.061 \\
Gumbel & -3.287 & 0.010 & 0.078 \\
Rotated Gumbel & -1.434 & 0.007 & 0.126 \\
Student & -4.288 & 0.766 & -165.082 \\
SJC & -3.408 & 3.557 & 37.320 \\
TVP-Gaussian & -2.013 & -2.416 & -145.130 \\
TVP-Clayton & -1.248 & -1.396 & 0.071 \\
TVP-rotated Clayton & -4.108 & -0.713 & 0.063 \\
TVP-Gumbel & -3.466 & -0.175 & -0.093 \\
TVP-rotated Gumbel & -1.946 & -0.868 & 0.128 \\
TVP-student & -4.623 & -1.680 & -170.553 \\
TVP-student 2 & $-\mathbf{5 . 2 1 1}$ & -1.858 & $-\mathbf{1 7 4 . 4 5 8}$ \\
TVP-SJC & -0.118 & 10.593 & 69.498 \\
\hline
\end{tabular}

Note: this table reports the AIC values of different copula functions. The AICs of the best-fitted copula functions (i.e., the minimum AICs) are bold and underlined.
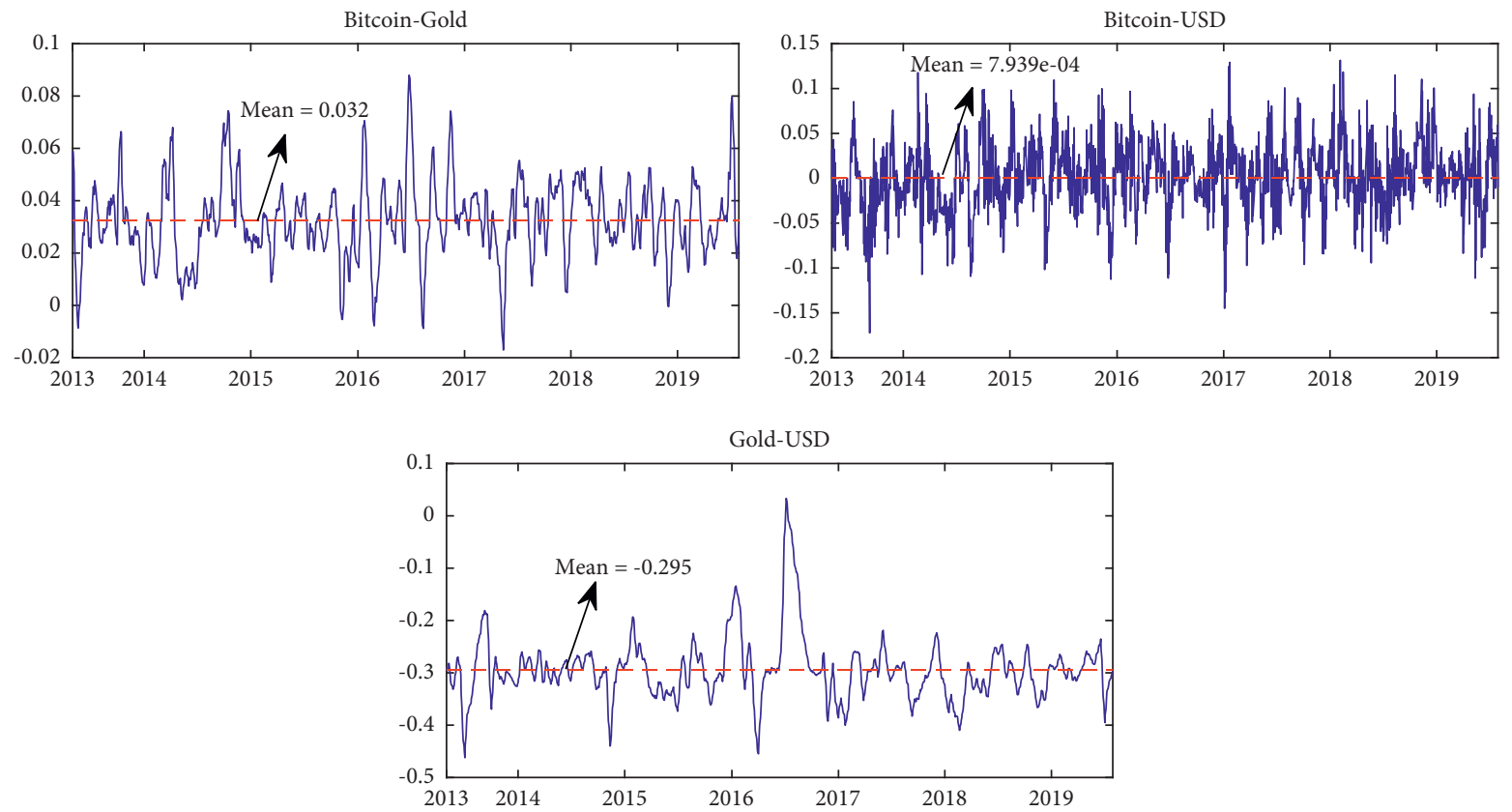

FIgURE 3: Time evolutions of the dependence of Bitcoin-gold, Bitcoin-USD, and gold-USD pairs. Note: the time-varying dependence structure is based on the best-fitted bivariate copula.

upside $\triangle \mathrm{CoVaRs}$ from Bitcoin to gold are larger than downside $\triangle C o V a R s$. Besides, downside $\triangle C o V a R s$ between gold and USD are smaller than upside $\Delta$ CoVaRs. These summary statistics indicates the possible existence of asymmetric downside and upside risk spillover between Bitcoin and gold markets and between gold and USD markets. Table 6 presents the results of KS test, which test the null hypothesis of equal upside and downside risk spillovers. Because the positive risk spillover between gold and Bitcoin dominates, and there is no positive risk spillover between gold and USD, we only explore the upside and downside asymmetry of the positive risk spillover between gold and
Bitcoin, and the negative risk spillover between gold and USD. As shown in column 2, the null hypothesis of symmetric positive upside and downside risk spillover between gold and Bitcoin can be rejected at $1 \%$ significant level. The results in column 3 also reject the null hypothesis of equal negative upside and downside risk spillover between gold and USD. The stronger downside risk spillover from gold to Bitcoin is due to the facts that the standardized residual of Bitcoin is left skewed. Similarly, because the standardized residuals of gold and USD are right skewed, the upside risk spillovers from Bitcoin to gold and between gold and USD are stronger. 

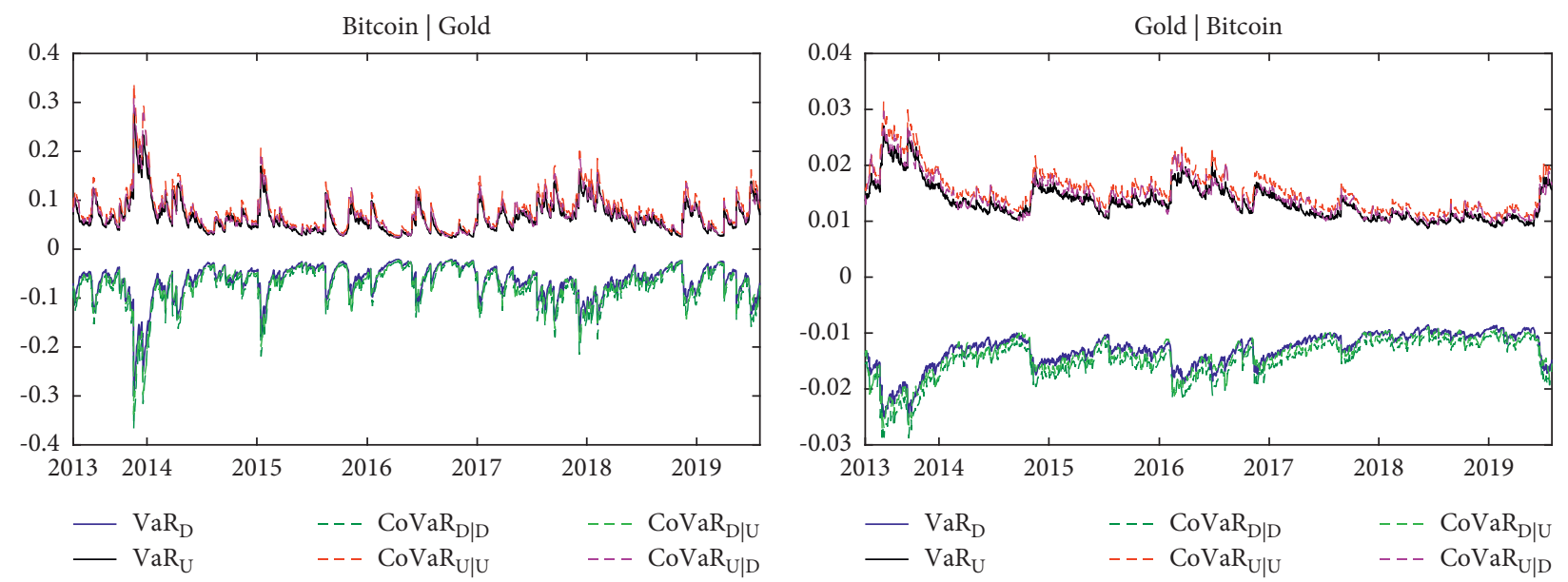

(a)
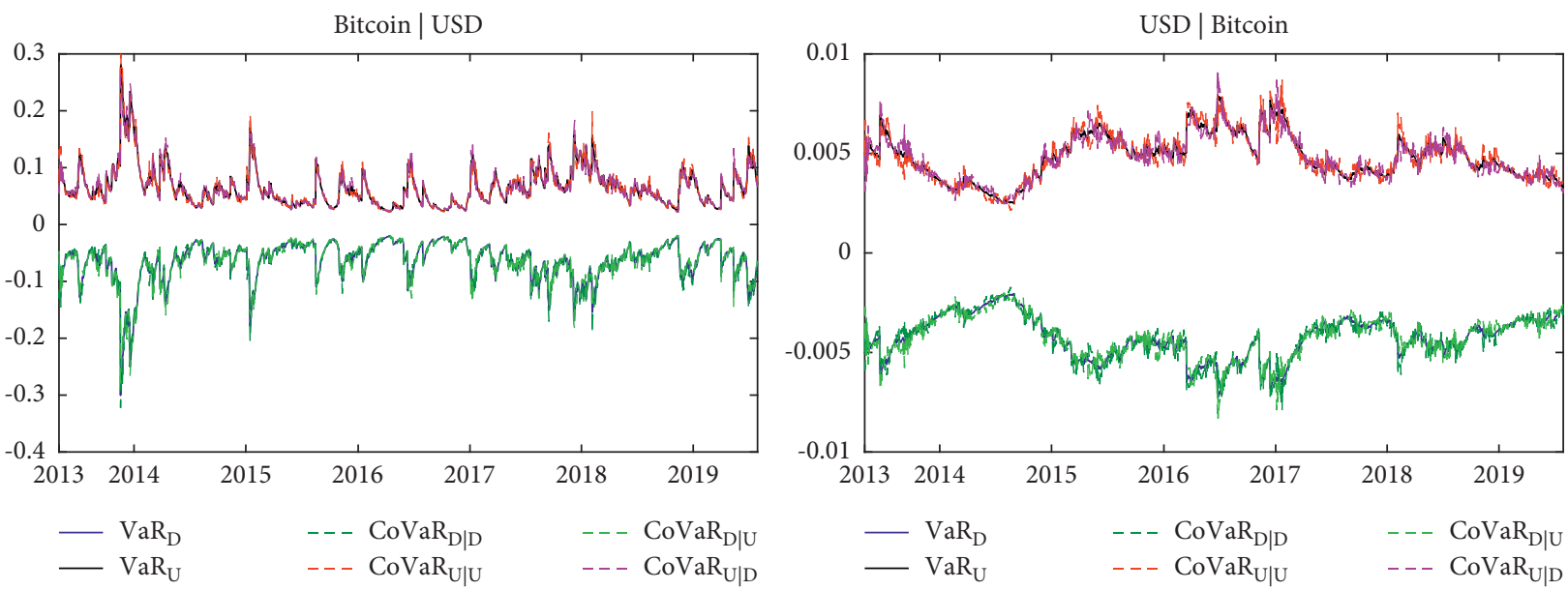

(b)
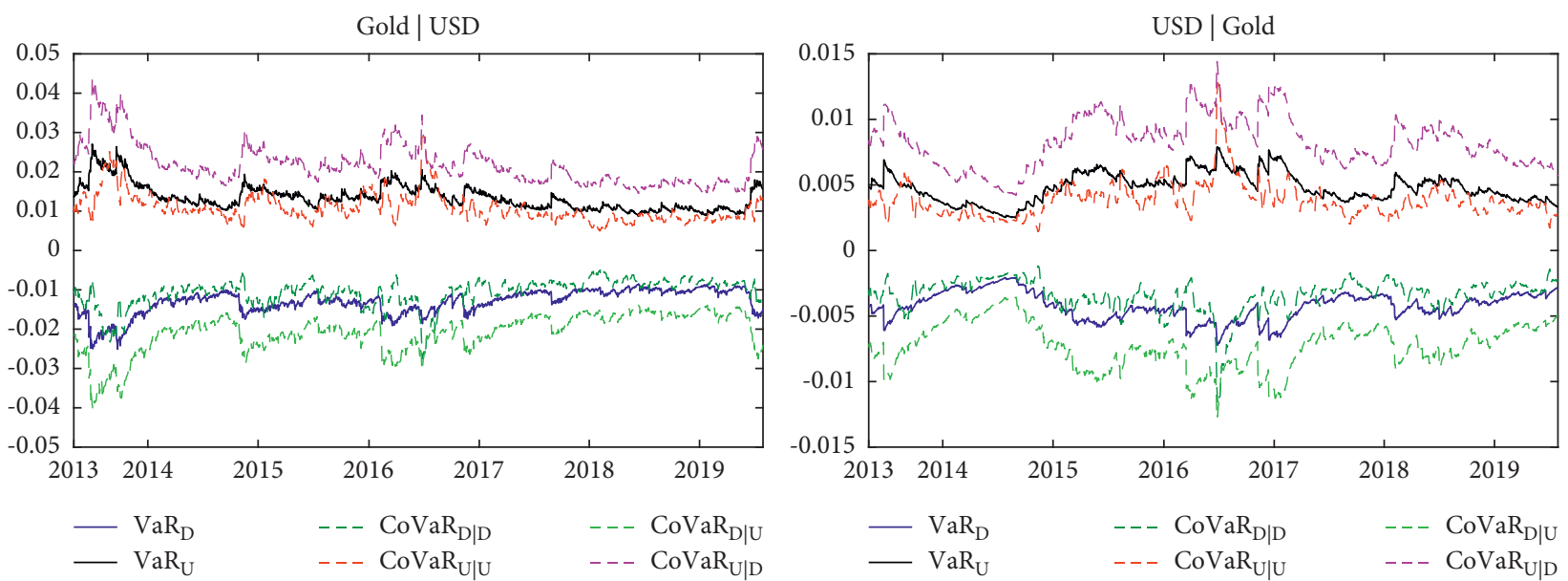

(c)

Figure 4: Downside and upside VaRs and CoVaRs. Note: Panel A shows the downside and upside VaRs and CoVaRs of Bitcoin-gold pair. Panel B shows the downside and upside VaRs and CoVaRs of Bitcoin-USD pair. Panel C shows the downside and upside VaRs and CoVaRs of gold-USD pair. $D$ and $U$ denote the downside and upside risk, respectively. $\mathrm{CoVaR}_{D \mid D}$ and $\mathrm{CoVaR}_{D \mid U}$ describe the downside risk of one

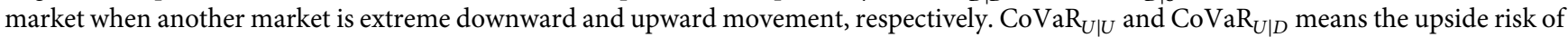
one market when another market facing the extreme upward and downward risk, respectively. (a) Panel A VaRs and CoVaRs of Bitcoin-gold pair. (b) Panel B VaRs and CoVaRs of Bitcoin-USD pair. (c) Panel C VaRs and CoVaRs of gold-USD pair. 
TABLE 4: Summary statistics for VaRs, CoVaRs, and $\Delta$ CoVaRs.

\begin{tabular}{|c|c|c|c|c|c|c|c|c|c|c|}
\hline \multirow{2}{*}{$\begin{array}{l}\text { Symbol } \\
1 \mid 2 \\
\end{array}$} & \multicolumn{5}{|c|}{ Downside } & \multicolumn{5}{|c|}{ Upside } \\
\hline & $\mathrm{VaR}_{1}^{D, \alpha}$ & $\mathrm{CoVaR}_{1 \mid 2 D}^{D, \alpha}$ & $\mathrm{CoVaR}_{1 \mid 2 U}^{D, \alpha}$ & $\Delta \operatorname{CoVaR}_{1 \mid 2 D}^{D, \alpha}$ & $\Delta \operatorname{CoVaR}_{1 \mid 2 U}^{D, \alpha}$ & $\mathrm{VaR}_{1}^{U, \alpha}$ & $\mathrm{CoVaR}_{1 \mid 2 U}^{U, \alpha}$ & $\mathrm{CoVaR}_{1 \mid 2 D}^{U, \alpha}$ & $\Delta \mathrm{CoVaR}_{1 \mid 2 U}^{U, \alpha}$ & $\Delta \mathrm{CoVaR}_{1 \mid 2 D}^{U, \alpha}$ \\
\hline Bitcoin|gold & $\begin{array}{l}-0.064 \\
(0.034)\end{array}$ & $\begin{array}{l}-0.079 \\
(0.042)\end{array}$ & $\begin{array}{l}-0.070 \\
(0.038)\end{array}$ & $\begin{array}{c}0.198 \\
(0.043)\end{array}$ & $\begin{array}{c}0.111 \\
(0.080)\end{array}$ & $\begin{array}{c}0.065 \\
(0.033)\end{array}$ & $\begin{array}{c}0.079 \\
(0.041)\end{array}$ & $\begin{array}{c}0.070 \\
(0.037)\end{array}$ & $\begin{array}{c}0.181 \\
(0.040)\end{array}$ & $\begin{array}{c}0.101 \\
(0.073)\end{array}$ \\
\hline $\begin{array}{l}\text { Gold| } \\
\text { Bitcoin }\end{array}$ & $\begin{array}{l}-0.013 \\
(0.003) \\
\end{array}$ & $\begin{array}{l}-0.015 \\
(0.004) \\
\end{array}$ & $\begin{array}{l}-0.014 \\
(0.003) \\
\end{array}$ & $\begin{array}{c}0.127 \\
(0.027) \\
\end{array}$ & $\begin{array}{c}0.073 \\
(0.051) \\
\end{array}$ & $\begin{array}{c}0.013 \\
(0.003) \\
\end{array}$ & $\begin{array}{c}0.016 \\
(0.004) \\
\end{array}$ & $\begin{array}{c}0.014 \\
(0.004) \\
\end{array}$ & $\begin{array}{c}0.134 \\
(0.028) \\
\end{array}$ & $\begin{array}{c}0.077 \\
(0.054) \\
\end{array}$ \\
\hline Bitcoin|USD & $\begin{array}{l}-0.064 \\
(0.034) \\
\end{array}$ & $\begin{array}{l}-0.065 \\
(0.036) \\
\end{array}$ & $\begin{array}{r}-0.064 \\
(0.034) \\
\end{array}$ & $\begin{array}{c}0.001 \\
(0.050) \\
\end{array}$ & $\begin{array}{l}-0.001 \\
(0.050) \\
\end{array}$ & $\begin{array}{c}0.065 \\
(0.033) \\
\end{array}$ & $\begin{array}{c}0.066 \\
(0.034) \\
\end{array}$ & $\begin{array}{c}0065 \\
(0.033) \\
\end{array}$ & $\begin{array}{c}0.001 \\
(0.046) \\
\end{array}$ & $\begin{array}{l}-0.000 \\
(0.046) \\
\end{array}$ \\
\hline USD $\mid$ Bitcoin & $\begin{array}{l}-0.004 \\
(0.001) \\
\end{array}$ & $\begin{array}{c}-0.004 \\
(0.001) \\
\end{array}$ & $\begin{array}{c}-0.004 \\
(0.001) \\
\end{array}$ & $\begin{array}{c}0.001 \\
(0.038) \\
\end{array}$ & $\begin{array}{l}-0.001 \\
(0.038) \\
\end{array}$ & $\begin{array}{c}0.005 \\
(0.001) \\
\end{array}$ & $\begin{array}{c}0.005 \\
(0.001) \\
\end{array}$ & $\begin{array}{c}0.005 \\
(0.001) \\
\end{array}$ & $\begin{array}{c}0.001 \\
(0.038) \\
\end{array}$ & $\begin{array}{l}-0.001 \\
(0.038) \\
\end{array}$ \\
\hline Gold|USD & $\begin{array}{l}-0.013 \\
(0.003) \\
\end{array}$ & $\begin{array}{l}-0.011 \\
(0.003) \\
\end{array}$ & $\begin{array}{l}-0.021 \\
(0.005) \\
\end{array}$ & $\begin{array}{l}-0.021 \\
(0.149) \\
\end{array}$ & $\begin{array}{c}0.415 \\
(0.035) \\
\end{array}$ & $\begin{array}{c}0.013 \\
(0.003) \\
\end{array}$ & $\begin{array}{c}0.011 \\
(0.004) \\
\end{array}$ & $\begin{array}{c}0.022 \\
(0.005) \\
\end{array}$ & $\begin{array}{l}-0.022 \\
(0.157) \\
\end{array}$ & $\begin{array}{c}0.436 \\
(0.036) \\
\end{array}$ \\
\hline USD|gold & $\begin{array}{l}-0.004 \\
(0.001) \\
\end{array}$ & $\begin{array}{l}-0.003 \\
(0.001) \\
\end{array}$ & $\begin{array}{l}-0.007 \\
(0.002)\end{array}$ & $\begin{array}{l}-0.020 \\
(0.163) \\
\end{array}$ & $\begin{array}{c}0.503 \\
(0.044) \\
\end{array}$ & $\begin{array}{c}0.005 \\
(0.001) \\
\end{array}$ & $\begin{array}{c}0.004 \\
(0.001) \\
\end{array}$ & $\begin{array}{c}0.008 \\
(0.002) \\
\end{array}$ & $\begin{array}{l}-0.020 \\
(0.164)\end{array}$ & $\begin{array}{c}0.508 \\
(0.043)\end{array}$ \\
\hline
\end{tabular}

Note: this table shows the means and the standard deviations (in parenthesis) of VaRs, CoVaRs and $\triangle$ CoVaRs of Bitcoin, gold, and USD. CoVaR $R_{1 \mid 2 D}^{D, \alpha}$ and $C o V a R_{1 \mid 2 U}^{D, \alpha}$ describe the downside risk of market 1 when market 2 is extreme downward and upward movement, respectively. CoVaR $R_{1 \mid 2 U}^{U, \alpha}$ and $\mathrm{CoVaR} R_{1 \mid 2 D}^{U, \alpha}$ are the upside risk of market 1 when market 2 facing the extreme upward and downward risk, respectively. $\Delta \mathrm{CoVaR} R_{1 \mid 2 D}^{D, \alpha}$ and $\Delta \mathrm{CoVaR} R_{1 \mid 2 U}^{\mathrm{D}, \alpha}$ are the risk contribution of the downward and upward movement of market 2 to the downward movement of market 1 , respectively. $\Delta C o V a R_{1 \mid 2 U}^{U, \alpha}$ and $\triangle \mathrm{CoVaR} R_{1 \mid 2 D}^{U, \alpha}$ are the risk contribution of the upward and downward movement of market 2 to the upward movement of market 1 , respectively.

\section{Short-Term and Long-Term Dependence and Risk Spillover}

In this section, we check the robustness in the main findings of Section 4 by exploring the short- and long-term dependence and risk spillover between the three assets through a variational mode decomposition (VMD) approach. Because our analysis above found no significant risk spillover effect between Bitcoin and USD, we just examine the shortand long-term dependence structure and risk spillover effect between Bitcoin and gold and between gold and USD.

5.1. Results for Short-Term and Long-Term Dependence. Before exploring the dependence and risk spillover of Bitcoin-gold and Bitcoin-USD pairs in short-term and longterm horizons, we utilized the variational mode decomposition (VMD) approach to distinguish the short-term and long-term dynamics of Bitcoin, gold, and USD return series. (The advantage of obtaining short-term and long-term sequences by VMD method is that this method can decompose the short-term and long-term variation trends implicit in the original sequence without loss of sample length.) The VMD method can be mathematically described as a solution of the constrained variational problem [66]:

$$
\begin{aligned}
& \min _{\left\{u_{k}\right\},\left\{\omega_{k}\right\}}=\left\{\sum_{k}\left\|\partial_{t}\left[\left(\delta(t)+\frac{j}{\pi t}\right) * u_{k}(t)\right] e^{-j \omega_{k} t}\right\|_{2}^{2}\right\}, \\
& \text { s.t. } \sum_{k} u_{k}=f
\end{aligned}
$$

where $k$ is the total number of modes; $u_{k}$ is the $k$ th mode; $\omega_{k}$ is the center frequency of the $k$ th mode; $\partial_{t}, \delta(t)$, and ${ }^{*}$ are the partial derivatives, the Dirac distribution and the convolution, respectively; $f$ is the original series. Then, the constraint in equation (28) is addressed by an augmented Lagrangian function:

$$
\begin{aligned}
\mathscr{L}\left(\left\{u_{k}\right\},\left\{\omega_{k}\right\}, \lambda\right)= & \alpha \sum_{k}\left\|\partial_{t}\left[\left(\delta(t)+\frac{j}{\pi t}\right) * u_{k}(t)\right]\right\|_{2}^{2} \\
& +\left\|f-\sum u_{k}\right\|_{2}^{2}+\left\langle\lambda, f-\sum u_{k}\right\rangle,
\end{aligned}
$$

where $\lambda$ is the Lagrange multiplier, $\alpha$ is the balancing parameter of the data-fidelity constraint, and $\|\bullet\|_{p}$ represents the usual vector $\ell_{p}$ norm where $p=2$. The solutions for $u$ and $\omega$ can be found in Fourier domain and updated by

$$
\begin{aligned}
& u_{n}^{n+1}=\frac{\left(f-\sum_{i \neq k} u_{i}+(\lambda / 2)\right)}{1+2 \alpha\left(\omega-\omega_{k}\right)^{2}}, \\
& \omega_{n}^{n+1}=\frac{\int_{0}^{\infty} \omega\left|u_{k}(\omega)\right|^{2} \mathrm{~d}_{\omega}}{\int_{0}^{\infty}\left|u_{k}(\omega)\right|^{2} \mathrm{~d}_{\omega}}
\end{aligned}
$$

respectively, where $n$ is the number of iterations, which is 500 for default. $\lambda$ in equations (29) and (30) is updated by

$$
\widehat{\lambda}^{n+1} \leftarrow \widehat{\lambda}^{n}+\tau\left(\widehat{f}-\sum_{k} \widehat{u}_{k}^{n+1}\right),
$$

until convergence: $\sum_{k}\left\|\widehat{u}_{k}^{n+1}-\widehat{u}_{k}^{n}\right\|_{2}^{2} /\left\|\widehat{u}_{k}^{n}\right\|_{2}^{2}$.

Following Lahmiri [67], Shahzad et al. [68], and Mensi et al. [46], the standardized residuals, $z_{t}$, obtained from the marginal models in Table 2 are decomposed into 10 subseries (i.e., $k=10$ ), which are compressed around ten different center frequencies. (The reason for this article to decompose the standardized residuals but not the raw return series is that the standardized residual series is an independent and identically distributed series with weak typical features like autocorrelation and heteroscedasticity. By decomposing the standardized residuals, the short-term and long-term 
TABLE 5: KS tests of difference between CoVaRs and VaRs.

\begin{tabular}{|c|c|c|c|c|}
\hline Symbol & & & & \\
\hline $1 \mid 2$ & $\begin{array}{l}H_{0}: \operatorname{CoVaR}_{1 \mid 2 D}^{D} \geq \operatorname{VaR}_{1}^{D, \alpha} \\
H_{1}: \operatorname{CoVaR}_{1 \mid 2 D}^{D}<\operatorname{VaR}_{1}^{D, \alpha}\end{array}$ & $\begin{array}{l}H_{0}: \operatorname{CoVaR}_{1 \mid 2 U}^{D, \alpha} \geq \operatorname{VaR}_{1}^{D, \alpha} \\
H_{0}: \operatorname{CoVaR}_{1 \mid 2 U}^{D, \alpha}<\operatorname{VaR}_{1}^{D, \alpha}\end{array}$ & $\begin{array}{l}H_{0}: \mathrm{CoVaR}_{1 \mid 2 U}^{U, \alpha} \leq \mathrm{VaR}_{1}^{U, \alpha} \\
H_{0}: \mathrm{CoVaR}_{1 \mid 2 U}^{U, \alpha}>\mathrm{VaR}_{1}^{U, \alpha}\end{array}$ & $\begin{array}{l}H_{0}: \mathrm{CoVaR}_{1 \mid 2 D}^{U, \alpha} \leq \mathrm{VaR}_{1}^{U, \alpha} \\
H_{0}: \mathrm{CoVaR}_{1 \mid 2 D}^{U, \alpha}>\operatorname{VaR}_{1}^{U, \alpha}\end{array}$ \\
\hline Bitcoin|gold & $\begin{array}{c}0.185 \\
{[0.000]}\end{array}$ & $\begin{array}{c}0.074 \\
{[0.000]}\end{array}$ & $\begin{array}{c}0.182 \\
{[0.000]}\end{array}$ & $\begin{array}{c}0.070 \\
{[0.000]}\end{array}$ \\
\hline Gold|Bitcoin & $\begin{array}{c}0.247 \\
{[0.000]}\end{array}$ & $\begin{array}{c}0.113 \\
{[0.000]}\end{array}$ & $\begin{array}{c}0.250 \\
{[0.000]}\end{array}$ & $\begin{array}{c}0.121 \\
{[0.000]}\end{array}$ \\
\hline Bitcoin|USD & $\begin{array}{c}0.015 \\
{[0.700]}\end{array}$ & $\begin{array}{c}0.022 \\
{[0.437]}\end{array}$ & $\begin{array}{c}0.018 \\
{[0.592]}\end{array}$ & $\begin{array}{c}0.022 \\
{[0.451]}\end{array}$ \\
\hline USD|Bitcoin & $\begin{array}{c}0.024 \\
{[0.385]}\end{array}$ & $\begin{array}{c}0.028 \\
{[0.291]}\end{array}$ & $\begin{array}{c}0.026 \\
{[0.355]}\end{array}$ & $\begin{array}{c}0.027 \\
{[0.310]}\end{array}$ \\
\hline Gold|USD & $\begin{array}{c}0.006 \\
{[0.953]} \\
\end{array}$ & $\begin{array}{c}0.735 \\
{[0.000]}\end{array}$ & $\begin{array}{c}0.006 \\
{[0.952]}\end{array}$ & $\begin{array}{c}0.756 \\
{[0.000]}\end{array}$ \\
\hline USD|gold & $\begin{array}{c}0.016 \\
{[0.641]}\end{array}$ & $\begin{array}{c}0.740 \\
{[0.000]}\end{array}$ & $\begin{array}{c}0.017 \\
{[0.646]}\end{array}$ & $\begin{array}{c}0.774 \\
{[0.000]}\end{array}$ \\
\hline
\end{tabular}

Note: this table lists the statistic and the $p$ value (in squared brackets) of the Kolmogorov-Smirnov (KS) tests, which verified the null hypothesis of no systemic risk spillover effect between Bitcoin, gold, and USD.

dependencies between two time series captured by copula functions would be less affected by their typical features.) Then, the ten modes are marked as VMD1 to VMD10 in the order of center frequency from small to large, in which the mode with the lowest center frequency (VMD1) is chosen to be the long-term series and the mode with the highest center frequency (VMD10) is used as the short-term series. The long-term dynamics (VMD1) and short-term dynamics (VMD10) for Bitcoin, gold, and USD are drawn in Figure 6.

Then, the short- and long-term dynamics of standardized residual series are employed to estimate the copula functions. The AIC of the copula functions based on short-term and longterm dynamics are listed in Table 7. Table 7 shows that the timevarying Gaussian copula function is the best-fitted one for describing the short-term and long-term dependence structure between gold and Bitcoin. The long-term dependence structure between gold and USD can be well described by the timevarying Gaussian copula function, whereas the short-term dependence between them can be well described by the Student$t$ copula with two time-varying parameters. Then, the dynamics of the best-fitted short-term and long-term dependencies are drawn in Panel A and Panel B of Figure 7, respectively. For the short-term dependence parameters drawn in Panel A of Figure 7, the dependence between gold and other two assets both fluctuate around a small average value, and the mean of the short-term dependence parameters between Bitcoin and gold and between gold and USD are 0.029 and -0.052 , respectively. For the long-term dependence parameters shown in Panel B of Figure 7, the dependence between Bitcoin and gold and between gold and USD fluctuate around 0.046 and -0.397 , respectively.

Overall, the short-term and long-term dependence between gold and USD are still stronger than those between Bitcoin and gold. Besides, the means of long-term dependence are stronger than those of short-term dependence, it reminds us that long-term investors should pay more attention to the dependency between gold and other two assets than short-term investors.
5.2. Tests for Short-Term and Long-Term Spillover Effect. To find the short-term and long-term risk spillover effect between Bitcoin and gold and between gold and USD, we measure CoVaRs based on short-term and long-term dependence structure and test the null hypothesis of no risk spillover between Bitcoin and gold and between gold and USD. The means and standard deviations are listed in columns 2-3 and columns 6-7 of Table 8, and the results of KS test, which test the hypothesis of no short-term and longterm risk spillover effects, are listed in Table 9. Table 9 firstly reject the null hypothesis of no positive and negative shortterm and long-term system risk spillover effect between Bitcoin and gold market, further indicating the instability of risk spillover between Bitcoin and gold. Besides, both the null hypothesis of no positive and negative short-term risk spillover between gold and USD are reject at $10 \%$ significant level, suggesting that the short-term risk spillover effect between gold and USD is instable. The null hypothesis of no positive long-term risk spillovers between gold and USD cannot be rejected, whereas the null hypothesis of no negative long-term risk spillovers is rejected at $1 \%$ significant level, indicating the stable long-term negative risk spillover between gold and USD.

Then, we measure $\Delta C o V a R$ s based on short-term and long-term dependence structure to quantify the short-term and long-term risk spillover effect between Bitcoin and gold and between gold and USD. The dynamics of short-term and long-term $\triangle \mathrm{CoVaRs}$ are drawn in Figure 8. (We only draw $\Delta \mathrm{CoVaR}_{1 \mid 2 D}^{D, \alpha}$ and $\Delta \mathrm{CoVaR}_{1 \mid 2 U}^{U, \alpha}$ for Bitcoin-gold pairs and $\triangle \operatorname{CoVaR}_{1 \mid 2 U}^{D, \alpha}$ and $\Delta \operatorname{CoVaR}_{1 \mid 2 D}^{U, \alpha}$ for gold-USD pairs.) The mean of them are list in columns 4-5 and columns 8-9 of Table 8 . We can find that both short-term and long-term $\Delta \operatorname{CoVaR}_{1 \mid 2 D}^{D, \alpha}$ and $\Delta \operatorname{CoVaR}_{1 \mid 2 U}^{U, \alpha}$ from gold to Bitcoin have positive mean, whereas the mean of $\Delta \mathrm{CoVaR}_{1 \mid 2 U}^{D, \alpha}$ and $\Delta \mathrm{CoVaR}_{1 \mid 2 D}^{U, \alpha}$ of them are negative, further suggesting the dominant of positive risk spillover from gold to Bitcoin. For the $\Delta C o V a R s$ from Bitcoin to gold, only the mean of short- 

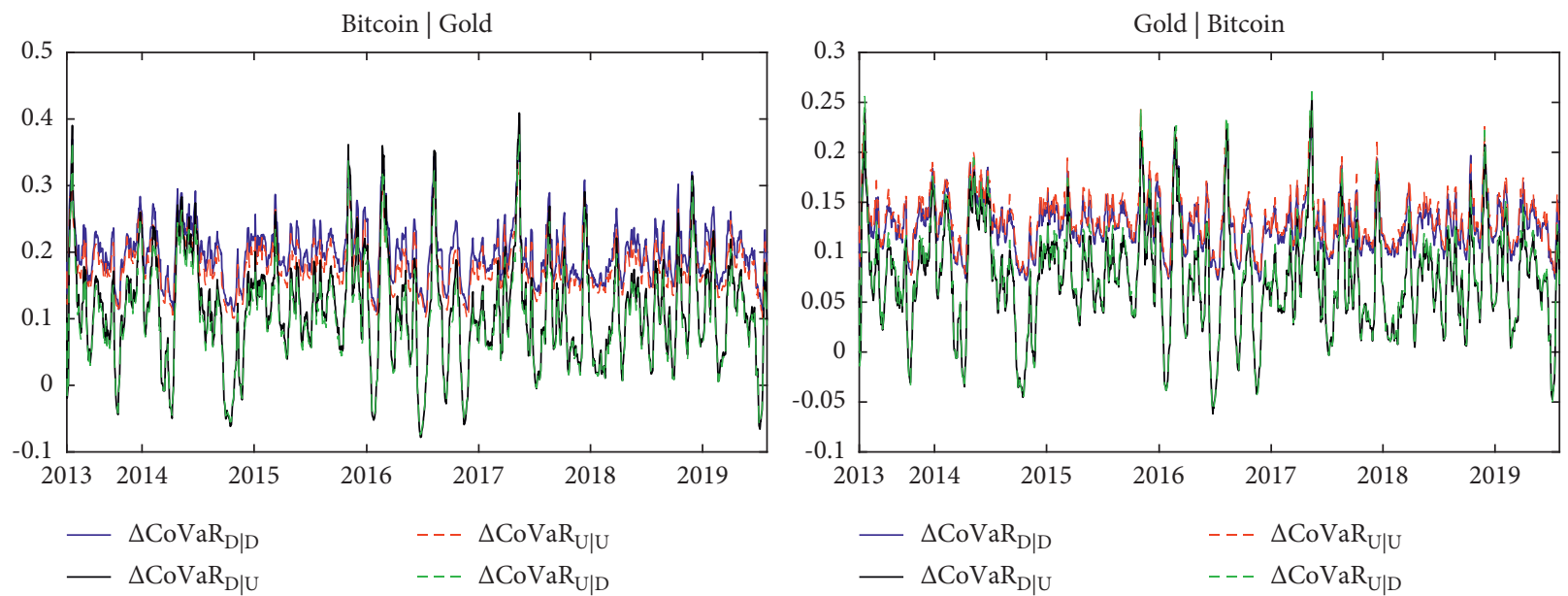

(a)
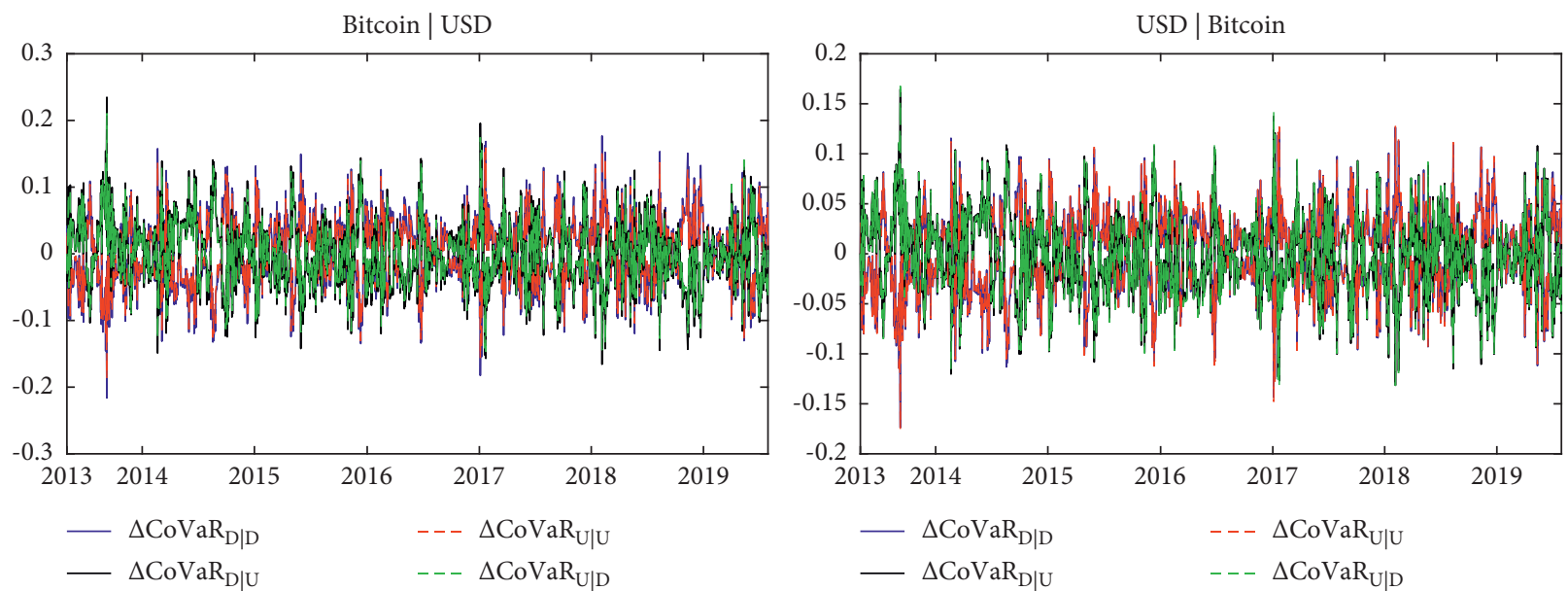

(b)
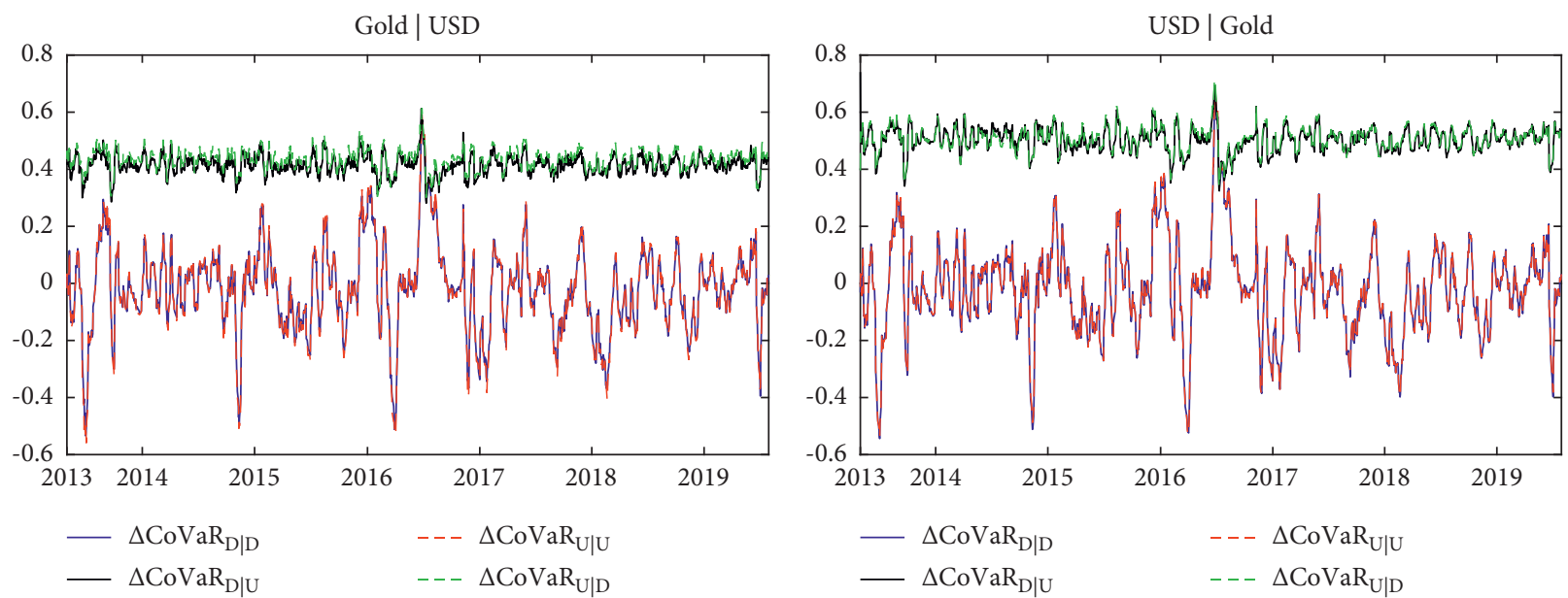

(c)

Figure 5: Downside and upside $\Delta$ CoVaRs. Note: Panel A shows the downside and upside $\Delta C o V a R s$ of Bitcoin-gold pair. Panel B shows the downside and upside $\Delta C o V a R s$ of Bitcoin-USD pair. Panel C shows the downside and upside $\Delta C o V a R s$ of gold-USD pair. $\Delta C o V a R_{1 \mid 2 D}^{D, \alpha}$ and $\triangle \mathrm{CoVaR}{ }_{1 \mid 2 U}^{D, \alpha}$ are the risk contribution of the downward and upward movement of market 2 to the downward movement of market 1 , respectively. $\Delta \mathrm{CoVaR}_{1 \mid 2 U}^{U, \alpha}$ and $\Delta \mathrm{CoVaR}_{1 \mid 2 D}^{U, \alpha}$ are the risk contribution of the upward and downward movement of market 2 to the upward movement of market 1, respectively. (a) Panel A $\triangle$ CoVaRs of Bitcoin-gold pair. (b) Panel B $\Delta$ CoVaRs of Bitcoin-USD pair. (c) Panel C $\triangle$ CoVaRs of gold-USD pair. 
TABLE 6: The KS tests for equalities of the downside and upside risk spillover effect.

\begin{tabular}{lcc}
\hline Symbol & $H_{0}: \Delta \operatorname{CoVaR}_{1 \mid 2 D}^{D, \alpha}=\Delta \operatorname{CoVaR}_{1 \mid 2 U}^{U, \alpha}$ & $H_{0}: \Delta \operatorname{CoVaR}_{1 \mid 2 U}^{D, \alpha}=\Delta \operatorname{CoVaR}_{1 \mid 2 D}^{U, \alpha}$ \\
$1 \mid 2$ & $H_{1}: \Delta \operatorname{CoVaR}_{1 \mid 2 D}^{D, \alpha} \neq \Delta \operatorname{CoVaR}_{1 \mid 2 U}^{U, \alpha}$ & $\mathbf{0 . 1 9 8}$ \\
$H_{1}: \Delta \operatorname{CoVaR}_{1 \mid 2 U}^{D, \alpha} \neq \Delta \operatorname{CoVaR}_{1 \mid 2 D}^{U, \alpha}$
\end{tabular}

Note: this table summary the statistic and the $p$ value (in squared brackets) of Kolmogorov-Smirnov (KS) test, testing the null hypothesis of equalities of the downside and upside $\triangle$ CoVaRs.
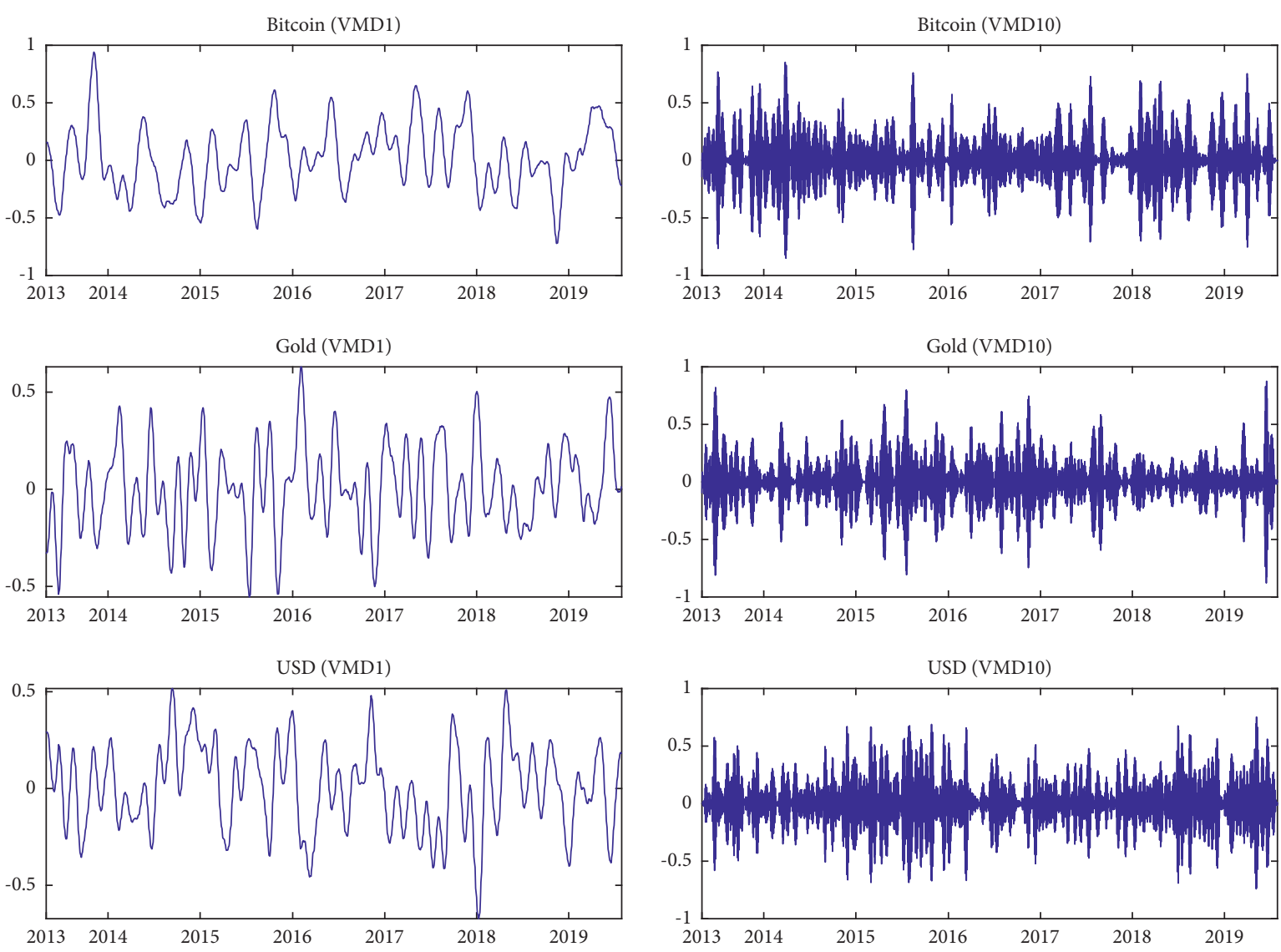

FIgURE 6: Results of the variational mode decomposition for the Bitcoin, gold, and USD series.

term $\Delta \operatorname{CoVaR}_{1 \mid 2 D}^{D, \alpha}$ and $\Delta \operatorname{CoVaR}_{1 \mid 2 U}^{U, \alpha}$ are positive, meaning the dominant of positive short-term risk spillover from Bitcoin to gold. Moreover, both short-term and long-term $\Delta \mathrm{CoVaR}_{1 \mid 2 U}^{D, \alpha}$ and $\Delta \mathrm{CoVaR}_{1 \mid 2 D}^{U, \alpha}$ between gold and USD have positive means, whereas both short-term and long-term
$\Delta \mathrm{CoVaR}_{1 \mid 2 D}^{D, \alpha}$ and $\Delta \operatorname{CoVaR}_{1 \mid 2 U}^{U, \alpha}$ between gold and USD have negative means, further indicating the major negative risk spillover effect between gold and USD. What's more, the mean of the long-term $\triangle C o V a R s$ between gold and USD are stronger than the short-term $\triangle C o V a R s$. 
TABLE 7: Results of copula functions based on short-term and long-term dynamics.

\begin{tabular}{lcccc}
\hline & \multicolumn{2}{c}{ Bitcoin and gold } & \multicolumn{2}{c}{ Gold and USD } \\
& Short term & Long term & Short term & Long term \\
\hline Gaussian & -3.101 & -4.370 & -23.055 & -368.472 \\
Clayton & -0.638 & 0.008 & 0.0284 & 0.119 \\
Rotated Clayton & -0.630 & 0.018 & 0.0286 & 0.116 \\
Gumbel & -0.070 & 0.031 & 0.047 & 0.189 \\
Rotated Gumbel & -0.063 & 0.002 & 0.047 & -192 \\
Student & -0.436 & -6.190 & -29.096 & -368.852 \\
SJC & 0.936 & 10.003 & -137.640 & $-\mathbf{0}$ \\
TVP-Gaussian & $-\mathbf{1 7 2 . 0 9 5}$ & $-\mathbf{4 4 5 . 3 1 6}$ & -43.128 & -406 \\
TVP-Clayton & -103.705 & -285.717 & -42.965 & -407.847 \\
TVP-rotated Clayton & -103.492 & -270.566 & -48.482 & -41.757 \\
TVP-Gumbel & -116.064 & -146.486 & -48.343 & -46.911 \\
TVP-rotated Gumbel & -116.223 & -324.886 & -137.062 & -50.494 \\
TVP-Student & -167.218 & -440.555 & $-\mathbf{1 3 8 . 3 5 6}$ & -537.223 \\
TVP-Student 2 & -158.283 & -420.278 & -180.610 & -514.019 \\
TVP-SJC & -167.651 & -180.610 & 107.045 \\
\hline
\end{tabular}

Note: this table reports the AIC values of different copula functions. The AICs of the best-fitted copula functions (i.e., the minimum AICs) are bold and underlined.
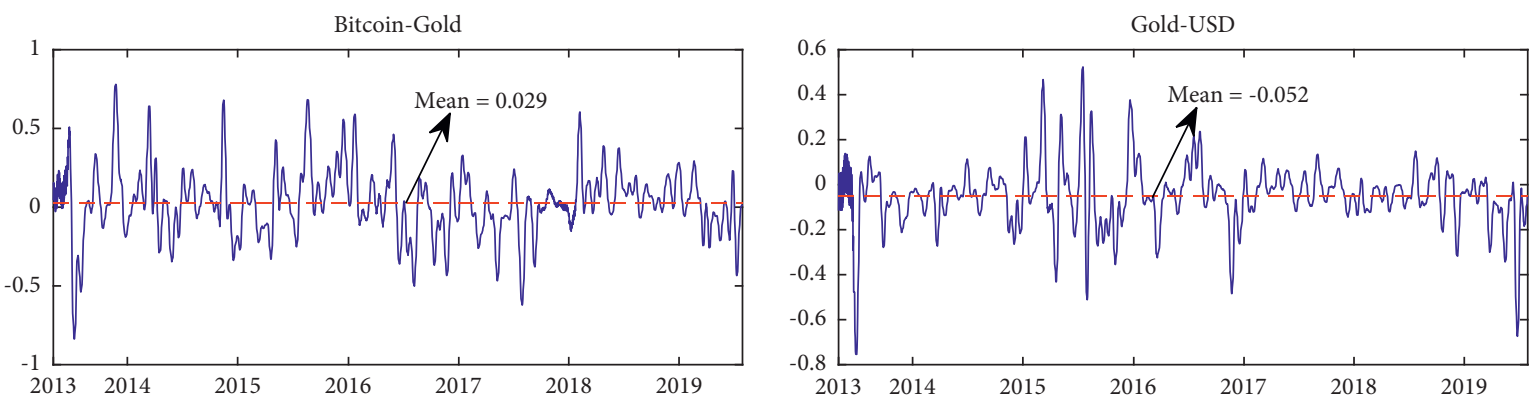

(a)
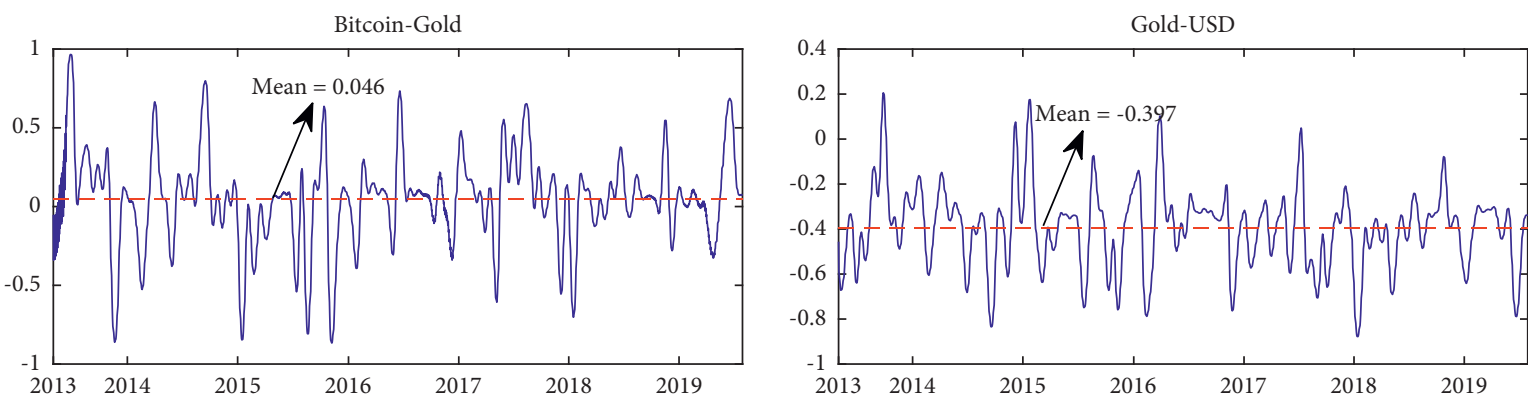

(b)

Figure 7: Time evolutions of short-term and long-term dependence between Bitcoin, USD, and gold returns. Note: the time-varying dependence structure is based on the best-fitted bivariate copula. (a) Panel A short-term dependence between Bitcoin and gold and between gold and USD. (b) Panel B long-term dependence between Bitcoin and gold and between gold and USD. 


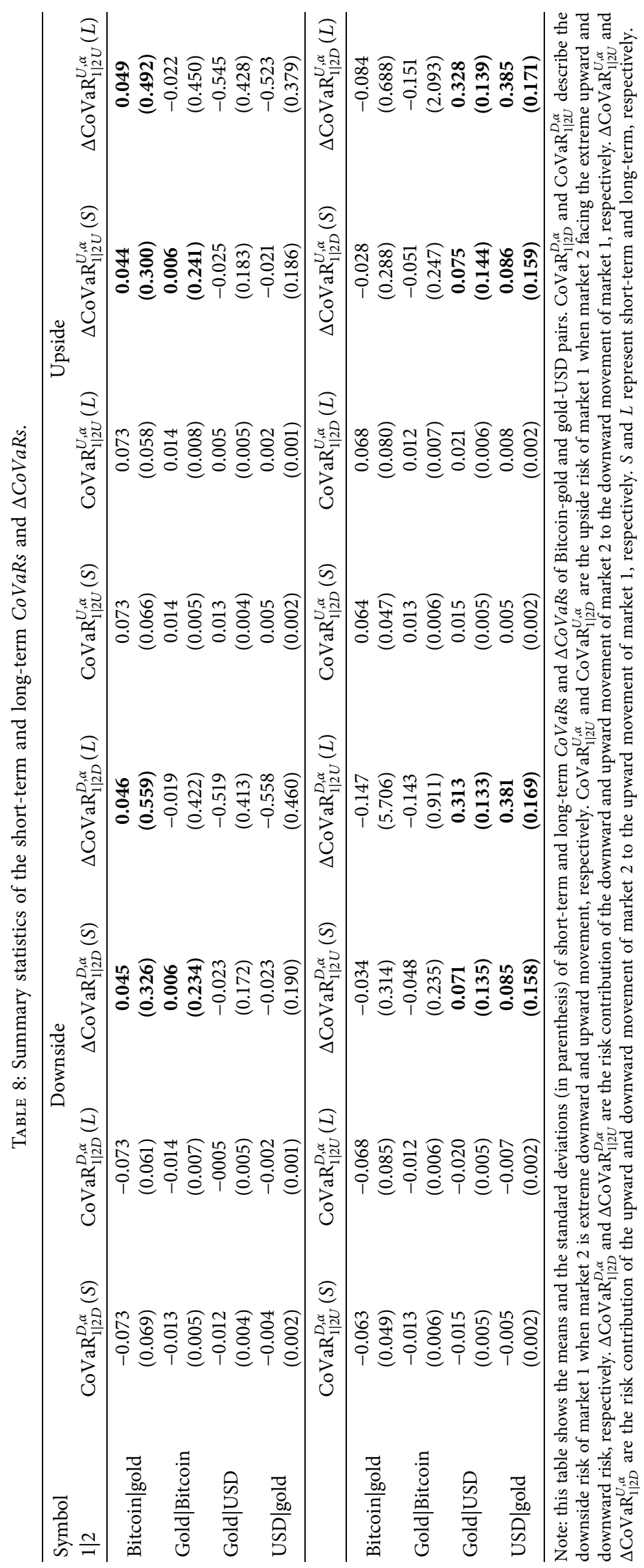


TABle 9: Results of the KS tests for the difference of short-term and long-term CoVaRs and VaRs.

\begin{tabular}{|c|c|c|c|c|c|c|c|c|}
\hline \multirow{4}{*}{$\begin{array}{l}\text { Symbol } \\
1 \mid 2\end{array}$} & \multicolumn{4}{|c|}{ Downside } & \multicolumn{4}{|c|}{ Upside } \\
\hline & \multirow{2}{*}{\multicolumn{2}{|c|}{$\begin{array}{l}H_{0}: \operatorname{CoVaR}_{1 \mid 2 D}^{D, \alpha} \geq \operatorname{VaR}_{1}^{D, \alpha} \\
H_{0}: \operatorname{CoVaR}_{1 \mid 2 D}^{D, \alpha}<\operatorname{VaR}_{1}^{D, \alpha}\end{array}$}} & \multirow{2}{*}{\multicolumn{2}{|c|}{$\begin{array}{l}H_{0}: \operatorname{CoVaR}_{1 \mid 2 U}^{D, \alpha} \geq \operatorname{VaR}_{1}^{D, \alpha} \\
H_{0}: \operatorname{CoVaR}_{1 \mid 2 U}^{D, \alpha}<\operatorname{VaR}_{1}^{D, \alpha}\end{array}$}} & \multirow{2}{*}{\multicolumn{2}{|c|}{$\begin{array}{l}H_{0}: \operatorname{CoVaR}_{1 \mid \alpha U}^{U, \alpha} \leq \operatorname{VaR}_{1}^{U, \alpha} \\
H_{0}: \operatorname{CoVaR}_{1 \mid 2 U}^{U, \alpha}>\operatorname{VaR}_{1}^{U, \alpha}\end{array}$}} & \multirow{2}{*}{\multicolumn{2}{|c|}{$\begin{array}{l}H_{0}: \operatorname{CoVaR}_{1 \mid 2 D}^{U, \alpha} \leq \operatorname{VaR}_{1}^{U, \alpha} \\
H_{0}: \operatorname{CoVaR}_{1 \mid 2 D}^{U, \alpha}>\operatorname{VaR}_{1}^{U, \alpha}\end{array}$}} \\
\hline & & & & & & & & \\
\hline & Short & Long & Short & Long & Short & Long & Short & Long \\
\hline Bitcoin|gold & $\begin{array}{c}0.082 \\
{[0.000]}\end{array}$ & $\begin{array}{c}0.107 \\
{[0.000]}\end{array}$ & $\begin{array}{c}0.046 \\
{[0.030]}\end{array}$ & $\begin{array}{c}0.068 \\
{[0.000]}\end{array}$ & $\begin{array}{c}0.076 \\
{[0.000]}\end{array}$ & $\begin{array}{c}0.105 \\
{[0.000]}\end{array}$ & $\begin{array}{c}0.046 \\
{[0.041]}\end{array}$ & $\begin{array}{c}0.064 \\
{[0.004]}\end{array}$ \\
\hline Gold|Bitcoin & $\begin{array}{c}0.110 \\
{[0.000]}\end{array}$ & $\begin{array}{c}0.162 \\
{[0.000]}\end{array}$ & $\begin{array}{c}0.078 \\
{[0.000]}\end{array}$ & $\begin{array}{c}0.062 \\
{[0.002]}\end{array}$ & $\begin{array}{c}0.119 \\
{[0.000]}\end{array}$ & $\begin{array}{c}0.179 \\
{[0.000]}\end{array}$ & $\begin{array}{c}0.083 \\
{[0.000]}\end{array}$ & $\begin{array}{c}0.067 \\
{[0.000]}\end{array}$ \\
\hline Gold|USD & $\begin{array}{c}0.043 \\
{[0.056]}\end{array}$ & $\begin{array}{c}0.006 \\
{[0.953]}\end{array}$ & $\begin{array}{c}0.153 \\
{[0.000]}\end{array}$ & $\begin{array}{c}0.635 \\
{[0.000]}\end{array}$ & $\begin{array}{c}0.040 \\
{[0.074]}\end{array}$ & $\begin{array}{c}0.006 \\
{[0.952]}\end{array}$ & $\begin{array}{c}0.166 \\
{[0.000]}\end{array}$ & $\begin{array}{c}0.651 \\
{[0.000]}\end{array}$ \\
\hline USD|gold & $\begin{array}{c}0.057 \\
{[0.009]}\end{array}$ & $\begin{array}{c}0.004 \\
{[0.960]}\end{array}$ & $\begin{array}{c}0.160 \\
{[0.000]}\end{array}$ & $\begin{array}{c}0.600 \\
{[0.000]}\end{array}$ & $\begin{array}{c}0.062 \\
{[0.002]}\end{array}$ & $\begin{array}{c}0.004 \\
{[0.969]}\end{array}$ & $\begin{array}{c}0.167 \\
{[0.000]}\end{array}$ & $\begin{array}{c}0.632 \\
{[0.000]}\end{array}$ \\
\hline
\end{tabular}

Note: this table lists the statistic and the $p$ value (in squared brackets) of the Kolmogorov-Smirnov (KS) tests, which verified the null hypothesis of no systemic risk spillover effect between Bitcoin and gold and between gold and USD.
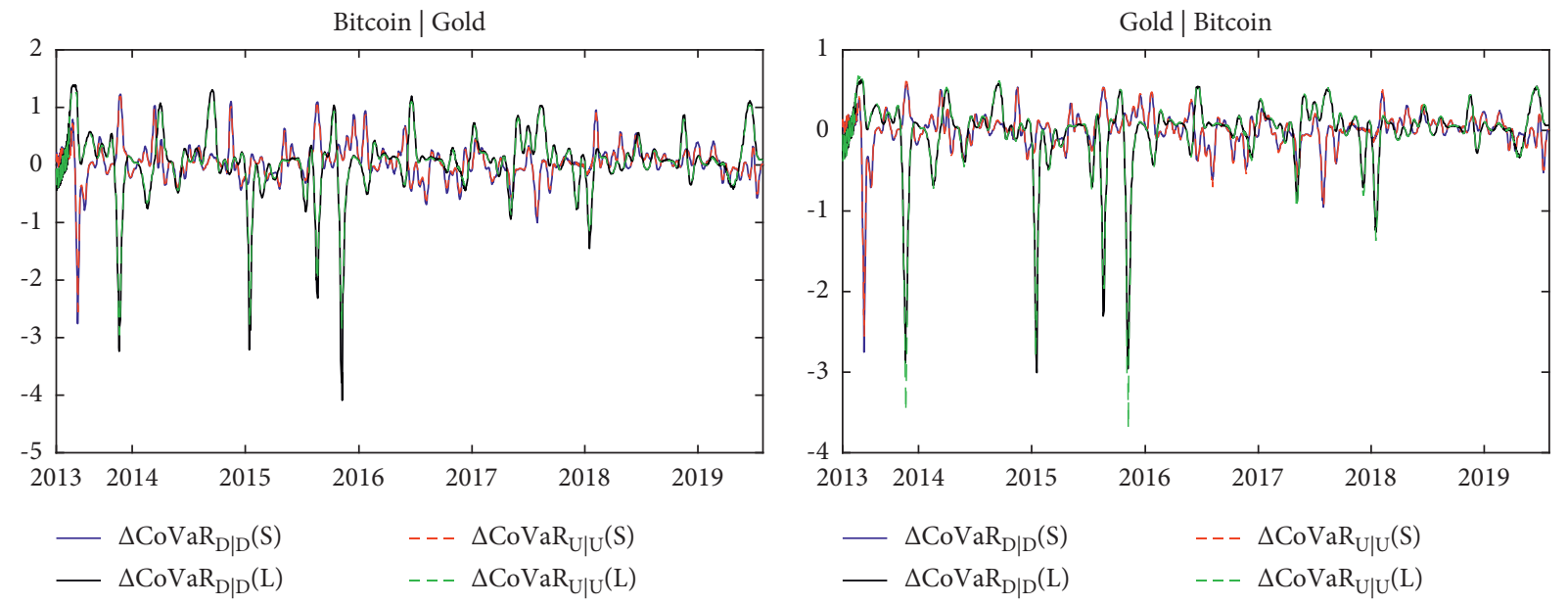

(a)
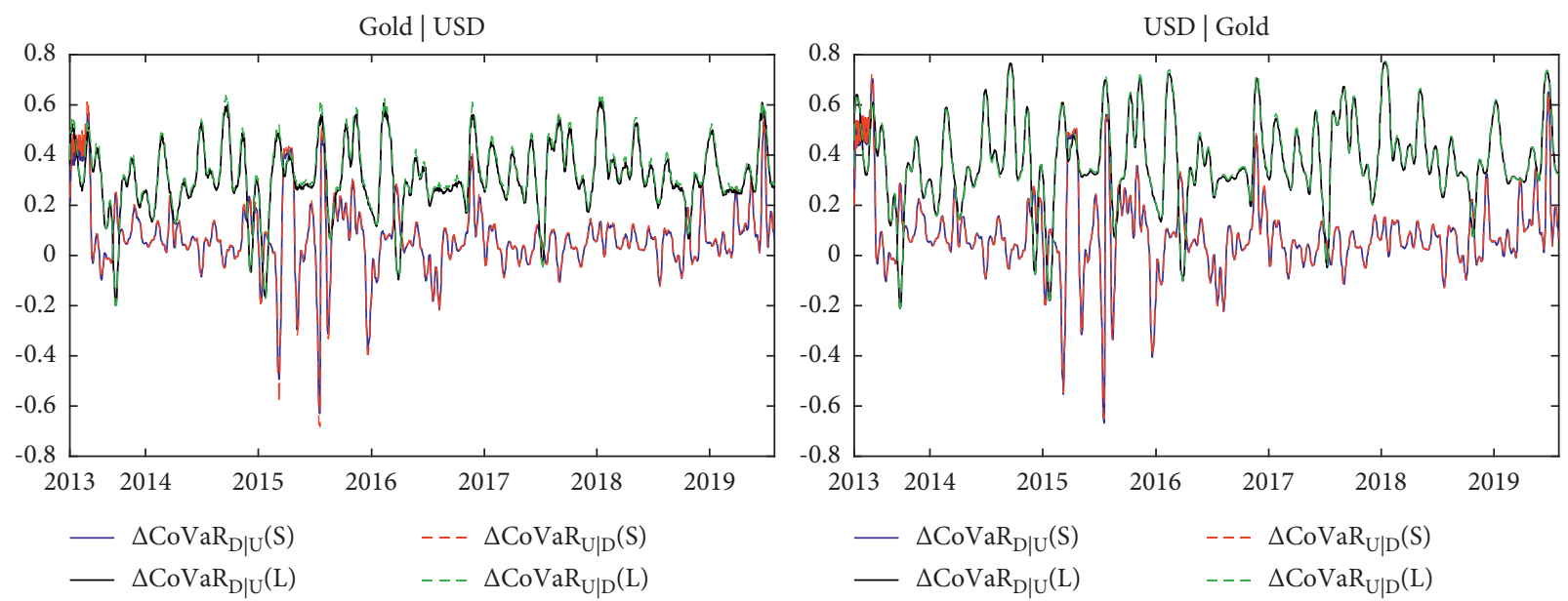

(b)

Figure 8: Short-term and long-term $\Delta$ CoVaRs. Notes: Panel A shows the short-term and long-term $\Delta$ CoVaRs of Bitcoin-gold pair. Panel B shows the short-term and long-term $\Delta C o V a R s$ of gold-USD pair. $\Delta \mathrm{CoVaR}_{1 \mid 2 D}^{D, \alpha}$ and $\Delta \mathrm{CoVaR}_{1 \mid 2 U}^{D, \alpha}$ are the risk contribution of the downward and upward movement of market 2 to the downward movement of market 1 , respectively. $\Delta \mathrm{CoVaR}_{1 \mid 2 U}^{U, \alpha}$ and $\Delta \mathrm{CoVaR}_{1 \mid 2 D}^{U, \alpha}$ are the risk contribution of the upward and downward movement of market 2 to the upward movement of market 1 , respectively. $\mathrm{S}$ and $\mathrm{L}$ denote the short-term and long-term $\triangle$ CoVaRs, respectively. (a) Panel A Short-term and long-term $\triangle$ CoVaRs of Bitcoin-gold pair. (b) Panel B Shortterm and long-term $\triangle$ CoVaRs of gold-USD pair. 


\section{Conclusions}

This article focuses on exploring the dependence structure and risk spillover effect between Bitcoin, gold, and USD. The dependence between Bitcoin, gold, and USD are captured using various static and dynamic copula functions, and the risk spillover effects are quantified with some measures and extensions about conditional Valueat-Risk $(\mathrm{CoVaR})$. Besides, we also utilize the variational mode decomposition (VMD) technology to explore the short-term and long-term dependence and risk spillover effect. The main findings are as follow.

Firstly, there is strongly negative dependence between gold and USD, whereas Bitcoin is weakly positively correlated with gold and nearly not correlated with USD. The positive dependence between Bitcoin and gold supports the findings of Jareño et al. [38], suggesting that Bitcoin has potential hedging ability like gold. Interesting, the risk spillover effect between Bitcoin and gold are not stable, that is, the downside and the upside risk of Bitcoin (gold) have the chance to increase when gold (Bitcoin) facing the downward or upward risk, but the positive risk spillovers are dominant. Thirdly, there is no risk spillover effect between Bitcoin and USD, but strong negative risk spillover between gold and USD. The results of the dependence and risk spillover between Bitcoin and USD confirm the findings about return and volatility spillover between Bitcoin and USD in Wang et al. [23]. The unstable risk spillover between Bitcoin and gold and the nonexistent risk spillover between Bitcoin and USD further demonstrate that Bitcoin may far less of a hedge than gold and USD, and it is more suitable for using as a speculative asset because of its high return and high volatility. Fourthly, the risk spillover between Bitcoin and gold and between gold and USD are asymmetric at downward and upward market environment. The downside risk spillover from gold to Bitcoin are stronger than the upside risk spillover, whereas the upside risk spillover from Bitcoin to gold and between gold and USD are stronger than the downside risk spillover. For the short-term and long-term risk spillover effect, the risk spillover effect between Bitcoin and gold are still unstable. Specially, the risk spillover effect between gold and USD are not stable in short-term horizons, whereas there is a stable negative risk spillover between them in longterm horizons. Combined with the fact that gold can be used as a hedge against a falling USD, this finding implies that gold can be used to hedge the long-term risk of USD but is not stable enough to hedge the short-term risk of the USD.

The findings of this article have several important implications for investors. Firstly, in the current economic and digital cryptocurrency trading environment, gold and USD continue to be the preferred safe-haven assets for investors. Secondly, due to the greater speculative nature of digital cryptocurrencies, investors have the opportunity to earn greater returns by investing in cryptocurrencies, but they also face greater risks. Therefore, investors should be cautious about Bitcoin investments. Besides, this article finds a potential hedging ability for Bitcoin but its hedging ability still needs to be strengthened. To strength the hedging ability of Bitcoin, policymakers need to speed up its legalization process and improve the systems related to the supply, management, and trading of Bitcoin. In addition, the stronger downside risk spillover from gold to Bitcoin means that Bitcoin investors with long positions face bigger risk than those with short positions. The stronger upside risk spillover from Bitcoin to gold means that gold investors with short positions face bigger risk than those with long positions. However, due to the instability of risk spillover between bitcoin and gold, bitcoin (gold) investors cannot use the abnormal changes in gold (bitcoin) price as a basis to judge whether they should close their positions in time. Moreover, the stronger upside risk spillover between gold and USD means that gold and USD investors with short positions both face bigger risk than those with long positions. Because there are primarily negative risk spillovers between gold and USD, gold investors with short positions should close their positions timely when steep fall of USD begins. Similarly, USD investors with short positions should close their positions timely when observing the start of steep fall in gold price, too. Finally, we conclude that gold can be used to hedge the long-term risk of USD but is not stable enough to hedge the short-term risk of USD. In fact, USD that is often referred to in the literatures is usually the USD index or the dollar exchange rate, which is the ratio of USD to other currencies. If the corresponding other currencies are not depreciating/appreciating at the consistent rate as USD, the USD and gold will rise and fall together in the short term. That is why we find gold an unstable hedge against USD in the short term. However, USD index and gold remain negatively correlated in the long term. As a result, we find that gold can hedge the long-term risk of USD. So, investors should make a broad judgment on the relative depreciation or appreciation rate of USD and local currencies before deciding whether to use USD as a hedge.

\section{Data Availability}

All data used in this article are publicly available. Bitcoin price was downloaded from https://coinmarketcap.com/. The gold prices and USD index are collected from Federal Reserve Bank of St. Louis (https://fred.stlouisfed.org/).

\section{Conflicts of Interest}

The authors declare no conflicts of interest in this article.

\section{Authors' Contributions}

J. Y. prepared the initial manuscript and the data collection. Y. S. offered the pivotal idea of this research and the literature review. X.-F. L. made the empirical model estimations and supervised the writing process of this paper. All authors have read and agreed to the published version of the manuscript.

\section{Acknowledgments}

This research was funded by the National Natural Science Foundation of China (71671145 and 71971191), Humanities and Social Science Fund of Ministry of Education of China (17YJA790015, 17XJA790002, 18YJC790132, and 
18XJA790002), Science and Technology Innovation Team of Yunnan Provincial Universities (2019014), and Yunnan Fundamental Research Projects (202001AS070018).

\section{References}

[1] M. Arfaoui and A. Ben Rejeb, "Oil, gold, US dollar and stock market interdependencies: a global analytical insight," European Journal of Management and Business Economics, vol. 26, no. 3, pp. 278-293, 2017.

[2] T. Conlon, B. M. Lucey, and G. S. Uddin, "Is gold a hedge against inflation? A wavelet time-scale perspective," Review of Quantitative Finance and Accounting, vol. 51, no. 2, pp. 317-345, 2017.

[3] A. Kaul and S. Sapp, "Y2K fears and safe haven trading of the U.S. dollar," Journal of International Money and Finance, vol. 25, no. 5, pp. 760-779, 2006.

[4] C.-S. Liu, M.-S. Chang, X. Wu, and C. M. Chui, "Hedges or safe havens-revisit the role of gold and USD against stock: a multivariate extended skew-tcopula approach," Quantitative Finance, vol. 16, no. 11, pp. 1763-1789, 2016.

[5] X. Ma, R. Yang, D. Zou, and R. Liu, "Measuring extreme risk of sustainable financial system using GJR-GARCH model trading data-based," International Journal of Information Management, vol. 50, pp. 526-537, 2020.

[6] A. A. Salisu and I. Adediran, "Gold as a hedge against oil shocks: evidence from new datasets for oil shocks," Resources Policy, vol. 66, Article ID 101606, 2020.

[7] A. A. Salisu, I. D. Raheem, and U. B. Ndako, "The inflation hedging properties of gold, stocks and real estate: a comparative analysis," Resources Policy, vol. 66, 2020.

[8] M. H. Shakil, I. H. M. Mustapha, M. Tasnia, and B. Saiti, "Is gold a hedge or a safe haven? An application of ARDL approach," Journal of Economics, Finance and Administrative Science, vol. 23, no. 44, pp. 60-76, 2018.

[9] S.-Y. Wang and S.-K. Lin, "The pricing and hedging of structured notes with systematic jump risk: an analysis of the USD knock-out reversed swap," International Review of Economics \& Finance, vol. 19, no. 1, pp. 106-118, 2010.

[10] X. Wen and H. Cheng, "Which is the safe haven for emerging stock markets, gold or the US dollar?" Emerging Markets Review, vol. 35, pp. 69-90, 2018.

[11] S. Nakamoto, "Bitcoin: a peer-to-peer electronic cash system," 2008, https://Bitcoin.org/Bitcoin.pdf.

[12] C. Baek and M. Elbeck, "Bitcoins as an investment or speculative vehicle? A first look," Applied Economics Letters, vol. 22, no. 1, pp. 30-34, 2014.

[13] D. G. Baur, K. Hong, and A. D. Lee, "Bitcoin: medium of exchange or speculative assets?" Journal of International Financial Markets, Institutions and Money, vol. 54, pp. 177-189, 2018.

[14] X. Gong and B. Lin, "Effects of structural changes on the prediction of downside volatility in futures markets," Journal of Futures Markets, vol. 41, no. 7, pp. 1124-1153, 2021.

[15] A. H. Dyhrberg, "Bitcoin, gold and the dollar-a GARCH volatility analysis," Finance Research Letters, vol. 16, pp. 8592, 2016a.

[16] E. Bouri, S. J. H. Shahzad, D. Roubaud, L. Kristoufek, and B. Lucey, "Bitcoin, gold, and commodities as safe havens for stocks: new insight through wavelet analysis," The Quarterly Review of Economics and Finance, vol. 77, 2020.

[17] D. Das, C. L. Le Roux, R. K. Jana, and A. Dutta, "Does Bitcoin hedge crude oil implied volatility and structural shocks? A comparison with gold, commodity and the US dollar," Finance Research Letters, vol. 36, Article ID 101335, 2020.

[18] A. H. Dyhrberg, "Hedging capabilities of Bitcoin. Is it the virtual gold?” Finance Research Letters, vol. 16, pp. 139-144, 2016.

[19] T. Klein, H. Pham Thu, and T. Walther, "Bitcoin is not the new gold-a comparison of volatility, correlation, and portfolio performance," International Review of Financial Analysis, vol. 59, pp. 105-116, 2018.

[20] A. Kliber, P. Marszałek, I. Musiałkowska, and K. Świerczyńska, "Bitcoin: safe haven, hedge or diversifier? Perception of bitcoin in the context of a country's economic situation-a stochastic volatility approach," Physica A: Statistical Mechanics and Its Applications, vol. 524, pp. 246-257, 2019.

[21] R. Selmi, W. Mensi, S. Hammoudeh, and J. Bouoiyour, "Is Bitcoin a hedge, a safe haven or a diversifier for oil price movements? A comparison with gold," Energy Economics, vol. 74, pp. 787-801, 2018.

[22] S. J. H. Shahzad, E. Bouri, D. Roubaud, L. Kristoufek, and B. Lucey, "Is Bitcoin a better safe-haven investment than gold and commodities?" International Review of Financial Analysis, vol. 63, pp. 322-330, 2019.

[23] G. Wang, Y. Tang, C. Xie, and S. Chen, "Is Bitcoin a safe haven or a hedging asset? Evidence from China," Journal of Management Science and Engineering, vol. 4, no. 3, pp. 173-188, 2019.

[24] R. Bedoui, S. Braiek, K. Guesmi, and J. Chevallier, "Retracted: on the conditional dependence structure between oil, gold and USD exchange rates: nested copula based GJR-GARCH model," Energy Economics, vol. 80, pp. 876-889, 2019.

[25] F. Capie, T. C. Mills, and G. Wood, "Gold as a hedge against the dollar," Journal of International Financial Markets, Institutions and Money, vol. 15, no. 4, pp. 343-352, 2005.

[26] H.-F. Chang, L.-C. Huang, and M.-C. Chin, "Interactive relationships between crude oil prices, gold prices, and the NTUS dollar exchange rate-A Taiwan study," Energy Policy, vol. 63, pp. 441-448, 2013.

[27] Q. He, Y. Guo, and J. Yu, "Nonlinear dynamics of gold and the dollar," The North American Journal of Economics and Finance, vol. 52, Article ID 101160, 2020.

[28] F.-L. Lin, Y.-F. Chen, and S.-Y. Yang, "Does the value of US dollar matter with the price of oil and gold? A dynamic analysis from time-frequency space," International Review of Economics \& Finance, vol. 43, pp. 59-71, 2016.

[29] B. Mo, H. Nie, and Y. Jiang, "Dynamic linkages among the gold market, US dollar and crude oil market," Physica A: Statistical Mechanics and Its Applications, vol. 491, pp. 984994, 2018

[30] P. Y. Ping, M. H. B. Ahmad, and N. B. Ismail, "Volatility spillover effect study in U.S. dollar and gold market based on bivariate-BEKK model," Advances in Industrial and Applied Mathematics, vol. 1750, Article ID 060006, 2016.

[31] J. C. Reboredo, "Is gold a safe haven or a hedge for the US dollar? Implications for risk management," Journal of Banking \& Finance, vol. 37, no. 8, pp. 2665-2676, 2013.

[32] S. K. Samanta and A. H. M. Zadeh, "Co-movements of oil, gold, the U.S. dollar, and stocks," Modern Economy, vol. 3, no. 1, pp. 111-117, 2012.

[33] Y. S. Wang and Y. L. Chueh, "Dynamic transmission effects between the interest rate, the US dollar, and gold and crude oil prices," Economic Modelling, vol. 30, pp. 792-798, 2013.

[34] Y. Wei, C. Liang, Y. Li, X. Zhang, and G. Wei, "Can CBOE gold and silver implied volatility help to forecast gold futures 
volatility in China? Evidence based on HAR and ridge regression models," Finance Research Letters, vol. 35, Article ID 101287, 2020.

[35] L. Bai, Y. Wei, G. Wei, X. Li, and S. Zhang, "Infectious disease pandemic and permanent volatility of international stock markets: a long-term perspective," Finance Research Letters, vol. 40, Article ID 101709, 2021.

[36] E. Bouri, M. Das, R. Gupta, and D. Roubaud, "Spillovers between Bitcoin and other assets during bear and bull markets," Applied Economics, vol. 50, no. 55, pp. 5935-5949, 2018.

[37] E. Bouri, R. Gupta, A. Lahiani, and M. Shahbaz, "Testing for asymmetric nonlinear short- and long-run relationships between Bitcoin, aggregate commodity and gold prices," Resources Policy, vol. 57, pp. 224-235, 2018.

[38] F. Jareño, M. d. 1. O. González, M. Tolentino, and K. Sierra, "Bitcoin and gold price returns: a quantile regression and NARDL analysis," Resources Policy, vol. 67, Article ID 101666, 2020.

[39] S. H. Kang, R. P. McIver, and J. A. Hernandez, "Co-movements between Bitcoin and gold: a wavelet coherence analysis," Physica A: Statistical Mechanics and its Applications, vol. 536, Article ID 120888, 2019.

[40] Y. Wei, S. Qin, X. Li, S. Zhu, and G. Wei, "Oil price fluctuation, stock market and macroeconomic fundamentals: evidence from China before and after the financial crisis," Finance Research Letters, vol. 30, pp. 23-29, 2019.

[41] H. S. Zwick and S. A. S. Syed, "Bitcoin and gold prices: a fledging long-term relationship," Theoretical Economics Letters, vol. 9, no. 7, pp. 2516-2525, 2019.

[42] T. Adrian and M. K. Brunnermeier, "CoVaR," The American Economic Review, vol. 106, no. 7, pp. 1705-1741, 2016.

[43] G. Boako and P. Alagidede, "Systemic risks spillovers and interdependence among stock markets: international evidence with covar-copulas," South African Journal of Economics, vol. 86, no. 1, pp. 82-112, 2018.

[44] G. Girardi and A. Tolga Ergün, "Systemic risk measurement: multivariate GARCH estimation of CoVaR," Journal of Banking \& Finance, vol. 37, no. 8, pp. 3169-3180, 2013.

[45] Q. Ji, E. Bouri, D. Roubaud, and S. J. H. Shahzad, "Risk spillover between energy and agricultural commodity markets: a dependence-switching CoVaR-copula model," Energy Economics, vol. 75, pp. 14-27, 2018.

[46] W. Mensi, S. Hammoudeh, S. J. H. Shahzad, and M. Shahbaz, "Modeling systemic risk and dependence structure between oil and stock markets using a variational mode decomposition-based copula method," Journal of Banking \& Finance, vol. 75, pp. 258-279, 2017.

[47] W. Mensi, A. Tiwari, E. Bouri, D. Roubaud, and K. H. AlYahyaee, "The dependence structure across oil, wheat, and corn: a wavelet-based copula approach using implied volatility indexes," Energy Economics, vol. 66, pp. 122-139, 2017.

[48] J. C. Reboredo and A. Ugolini, "Systemic risk in European sovereign debt markets: a CoVaR-copula approach," Journal of International Money and Finance, vol. 51, pp. 214-244, 2015.

[49] X. Sun, C. Liu, J. Wang, and J. Li, “Assessing the extreme risk spillovers of international commodities on maritime markets: a GARCH-Copula-CoVaR approach," International Review of Financial Analysis, vol. 68, Article ID 101453, 2020.

[50] Q. Ji, B.-Y. Liu, H. Nehler, and G. S. Uddin, "Uncertainties and extreme risk spillover in the energy markets: a timevarying copula-based CoVaR approach," Energy Economics, vol. 76, pp. 115-126, 2018.
[51] Q. Ji, B.-Y. Liu, and Y. Fan, "Risk dependence of CoVaR and structural change between oil prices and exchange rates: a time-varying copula model," Energy Economics, vol. 77, pp. 80-92, 2019.

[52] C. Brooks, Introductory Econometrics for Finance, Cambridge University Press, Cambridge, UK, 2002.

[53] B. E. Hansen, "Autoregressive conditional density estimation," International Economic Review, vol. 35, no. 3, pp. 705-730, 1994.

[54] M. Sklar, "Fonctions de répartition à $\mathrm{n}$ dimensions et leurs marges," Publications de l'Institut Statistique de l'Universite de Paris, vol. 8, pp. 229-231, 1959.

[55] A. J. Patton, "Modelling asymmetric exchange rate dependence*," International Economic Review, vol. 47, no. 2, pp. 527-556, 2006.

[56] T. Berger and G. S. Uddin, "On the dynamic dependence between equity markets, commodity futures and economic uncertainty indexes," Energy Economics, vol. 56, pp. 374-383, 2016.

[57] R. Jammazi and J. C. Reboredo, "Dependence and risk management in oil and stock markets. A wavelet-copula analysis," Energy, vol. 107, pp. 866-888, 2016.

[58] J. C. Reboredo and A. Ugolini, "Quantile dependence of oil price movements and stock returns," Energy Economics, vol. 54, pp. 33-49, 2016.

[59] B. Tong, C. Wu, and C. Zhou, "Modeling the co-movements between crude oil and refined petroleum markets," Energy Economics, vol. 40, pp. 882-897, 2013.

[60] O. C. D. Silva Filho, F. A. Ziegelmann, and M. J. Dueker, "Modeling dependence dynamics through copulas with regime switching," Insurance: Mathematics and Economics, vol. 50, no. 3, pp. 346-356, 2012.

[61] A. Abadie, "Bootstrap tests for distributional treatment effects in instrumental variable models," Journal of the American Statistical Association, vol. 97, no. 457, pp. 284-292, 2002.

[62] C. M. Jarque and A. K. Bera, "A test for normality of observations and regression residuals," International Statistical Review/Revue Internationale de Statistique, vol. 55, no. 2, pp. 163-172, 1987.

[63] D. A. Dickey and W. A. Fuller, "Distribution of the estimators for autoregressive time series with a unit root," Journal of the American Statistical Association, vol. 74, no. 366a, pp. 427431, 1979.

[64] G. M. Ljung and G. E. P. Box, "On a measure of lack of fit in time series models," Biometrika, vol. 65, no. 2, pp. 297-303, 1978.

[65] R. F. Engle, "Autoregressive conditional heteroscedasticity with estimates of the variance of United Kingdom inflation," Econometrica, vol. 50, no. 4, pp. 987-1008, 1982.

[66] K. Dragomiretskiy and D. Zosso, "Variational mode decomposition," IEEE Transactions on Signal Processing, vol. 62, no. 3, pp. 531-544, 2014.

[67] S. Lahmiri, "Long memory in international financial markets trends and short movements during 2008 financial crisis based on variational mode decomposition and detrended fluctuation analysis," Physica A: Statistical Mechanics and Its Applications, vol. 437, pp. 130-138, 2015.

[68] S. J. H. Shahzad, R. R. Kumar, S. Ali, and S. Ameer, "Interdependence between Greece and other European stock markets: a comparison of wavelet and VMD copula, and the portfolio implications," Physica A: Statistical Mechanics and Its Applications, vol. 457, pp. 8-33, 2016. 